\title{
Delineating Urban Functional Zones Using U-Net Deep Learning: Case Study of Kuancheng District, Changchun, China
}

\author{
Yuewen Yang ${ }^{1,2}$, Dongyan Wang ${ }^{1, *}$, Zhuoran Yan $^{1}$ and Shuwen Zhang ${ }^{2}$ \\ 1 College of Earth Sciences, Jilin University, Changchun 130061, China; ywyang19@mails.jlu.edu.cn (Y.Y.); \\ yanzr19@mails.jlu.edu.cn (Z.Y.) \\ 2 Northeast Institute of Geography and Agroecology, Chinese Academy of Sciences, Changchun 130012, China; \\ zhangshuwen@iga.ac.cn \\ * Correspondence: wang_dy@jlu.edu.cn
}

Citation: Yang, Y.; Wang, D.; Yan, Z.; Zhang, S. Delineating Urban Functional Zones Using U-Net Deep Learning: Case Study of Kuancheng District, Changchun, China. Land 2021, 10, 1266. https://doi.org// 10.3390land 10111266

Academic Editor: Robert Gilmore Pontius, Jr.

Received: 5 September 2021

Accepted: 16 November 2021

Published: 19 November 2021

Publisher's Note: MDPI stays neutral with regard to jurisdictional claims in published maps and institutional affiliations.

Copyright: (c) 2021 by the authors. Licensee MDPI, Basel, Switzerland. This article is an open access article distributed under the terms and conditions of the Creative Commons Attribution (CC BY) license (https:// creativecommons.org/licenses/by/ $4.0 /)$.

\begin{abstract}
Scientific functional zone planning is the key to achieving long-term development goals for cities. The rapid development of remote sensing technology allows for the identification of urban functional zones, which is important since they serve as basic spatial units for urban planning and functioning. The accuracy of three methods-kernel density estimation, term frequency-inverse document frequency, and deep learning-for detecting urban functional zones was investigated using the Gaode points of interest, high-resolution satellite images, and OpenStreetMap. Kuancheng District was divided into twenty-one functional types (five single functional types and twenty mixed ones). The results showed that an approach using deep learning had a higher accuracy than the other two methods for delineating four out of five functions (excluding the commercial function) when compared with a field survey. The field survey showed that Kuancheng District was progressing towards completing the goals of the Land-Use Plan of the Central City of Changchun (2011-2020). Based on these findings, we illustrate the feasibility of identifying urban functional areas and lay out a framework for transforming them. Our results can guide the adjustment of the urban spatial structure and provide a reference basis for the scientific and reasonable development of urban land-use planning.
\end{abstract}

Keywords: urban functional zone; U-Net; spatial distribution; Kuancheng District

\section{Introduction}

Urban spaces are places where urban residents live, work, and relax. According to the place-based theory [1], an urban space comprises multiple functional zones that serve different purposes. Urban functional zones were first proposed in the Athens Charter [2] and are important space carriers for realizing urban socioeconomic functions. They provide precise boundaries for urban planning and management that can support infrastructure construction, coordinated regional development [3], and the environmental governance of projects (e.g., highway construction and other essential public services) [3,4]. In addition to influencing the urban process [5], urban functional zones can also be considered a suitable monitoring unit of urban sustainability [6]. The scientific delimitation of urban functional zones is conducive to the rational control of urban sprawl and the formulation of urban planning - which can provide ideas, strategies, frameworks, and guidelines to the government for urban development-as well as being important for supporting sustainable urban development, efficient planning, and accurate industrial distribution.

Research related to the urban functional zone focused on identifying said zones and their related applications. Urban functional zones are widely used in urban studies, such as heavy metal pollution [7], population density [8], urban heat island [9], air pollution [10], and traffic congestion [11].

Rapid urbanization has made the identification of urban functional zones a popular research topic. Traditional methods have relied on field surveys and remote-sensing 
images [12,13]. However, crowdsourced geographic information (e.g., point-of-interest, mobile, and traffic-flow data) provides a new channel for describing and understanding urban spatial structures [4,14-21]. Combining these two types of methods can make the identification of urban functional areas more accurate [22-25]. Identification methods include probability estimation approaches (e.g., kernel density estimation), as well as machine learning methods, such as Latent Dirichlet allocation (LDA) [18,20], support vector machines (SVM) [26], clustering algorithms [20,27], and neural networks [28]. An AI-based approach in the field of machine learning [29], deep learning uses a deep neural network (DNN) to learn object features from massive datasets, enabling it to recognize objects [30]. Deep learning has advanced research in many fields, including object classification [31], target detection [32,33], and semantic segmentation [34,35]. A major advantage of deep learning is that it automatically learns feature information from a large amount of image data [23], which can provide new avenues for research on the semantic segmentation of remote-sensing images. Among these, the most widely used models are convolutional neural networks $[23,28,31,36]$. Despite this, only a few studies have used deep learning to recognize urban-function areas. This is because it is time-consuming to manually select segmentation parameters and extract object features; moreover, the formation of urban functional areas is influenced by many factors, such as nature, the economy, history, and society.

Related studies have typically focused on economically developed cities, such as Beijing [19,26,27,37], Shenzhen [25,36,38], Guangzhou [14,39], Wuxi [40], and New York [41]. While Klapka and Halás [17,42] studied urban functional zones in the Czech Republic, few studies have focused on old industrial cities (except for Wuhan [20]) and Rust Belt cities. In particular, Changchun, the central city of the Northeast Asia economic circle, is a leading area for industrial transformation in Northeast China and strategic cooperation with Northeast Asia; there, rapid urban expansion has led to the disordered distribution of urban functional areas [43]. As such, there is an urgent need to improve the functional zoning of Changchun.

This study adopted a U-Net model and used high-resolution remote-sensing images to identify specific urban functional zones, including residential zones (RN), commercial and commercial services facilities zones $(\mathrm{CN})$, public administration and public service zones (PN), industrial and mining storage zones (IN), and ecological zones (EN). Using kernel density estimation based on point-of-interest data, we aimed to discover the overlay of urban functional zones. Finally, a confusion matrix was used to verify accuracy. This study introduced the U-Net model of deep learning to investigate urban functional zones, which can effectively identify them and avoid the problem of reduced accuracy caused by the absence of POI in old industrial cities, especially suburbs. The results can guide the adjustment of the urban spatial structure from the macro and are beneficial to the layout, coordination, and matching of the city's overall function, which can provide an effective reference for sustainable urban planning and development. Further, the method appears to be practical for mapping urban functional zones for application in other cities with similar socioeconomic attributes. It could even be used to map urban functional zones for earlier years if early remote-sensing images are available.

\section{Materials and Methods}

\subsection{Study Area}

This study used the Kuancheng District of Changchun, China, which spreads from rural-urban fringe areas to urban areas (Figure 1). Kuancheng District is located in the north of Changchun, with an urban area of $245 \mathrm{~km}^{2}$. It is in the transition zone between the eastern mountainous humid region and the western-plain semiarid region, belonging to the temperate continental subhumid monsoon climate type. The terrain in the area is relatively flat, with a large distribution of typical black soil resources. As one of the main districts of Changchun, Kuancheng is one of the city's earliest urban districts. It 
is recognized by China's Ministry of Civil Affairs as an experimental zone for national community governance and service innovation.

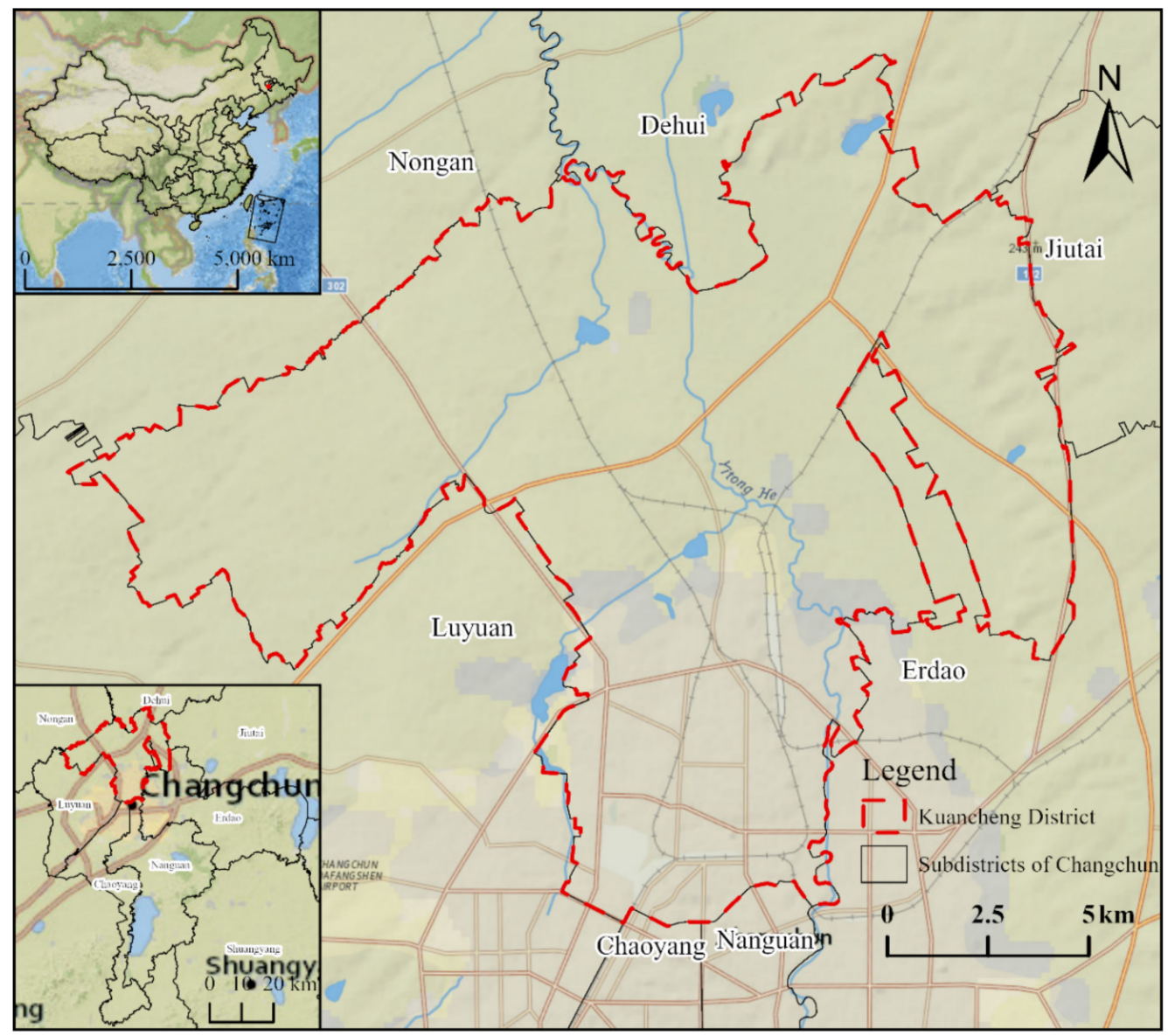

Figure 1. Location of Kuancheng District.

\subsection{Data Processing}

Data for administrative divisions were obtained from the National Bureau of Statistics of China. We employed a GaoFen-2 (GF-2) image covering the study area that was acquired in September 2019. Using ENVI 5.3, images with a resolution of $3.24 \mathrm{~m}$ in the multispectral GF-2 image were merged with images with a panchromatic resolution of $0.8 \mathrm{~m}$ to produce a pan-sharpened image of $1 \mathrm{~m}$ resolution with four bands. Field survey data were obtained from the GF-2 image by visual interpretation manually and field investigation.

Road-network data for Kuancheng District were collected from OpenStreetMap (OSM), a popular volunteer geographic information (VGI) source that provides free, open geographical data. The data are in vector format and contain different classes of streets, consisting of the following: motorway, motorway_link, primary, primary_link, tertiary, tertiary_link, secondary, pedestrian, residential, footway, track, trunk, and service, which form the boundary of functional zones.

In addition, point-of-interest (POI) data can record the geospatial and attribute information of a single point [21] (e.g., a house, store, or bus stop). After removing duplicate samples, we obtained a dataset of 17,665 POI data points indicating the functional and locational properties of sites as of 30 September 2020. These were generated from Gaode Map Services (https: / / ditu.amap.com / (accessed on 30 September 2020)), a well-known map service provider in China. In the POI dataset, there were 23 labels in the top-level category, 264 in the second-level category, and 869 in the third-level category. Based on the Code for Classification of Urban Land Use and Planning Standards of Development Land (GB 50137-2011), the POI dataset was divided into five labels at the first level (i.e., RN, CN, 
PN, IN, and EN) and twenty-two at the second level (see Appendix A), where roads and traffic facilities were abandoned since the elementary unit was divided by roads.

\subsection{Method}

Figure 2 shows the study framework. A traffic network is the skeleton of the urban functional area; thus, the OSM road network was first used to segment the study area. Next, hotspot analysis was conducted based on POI data, and we then compared the results derived from the U-Net deep learning (UDL), kernel density estimation (KDE), and term frequency-inverse document frequency (TF-IDF) methods.

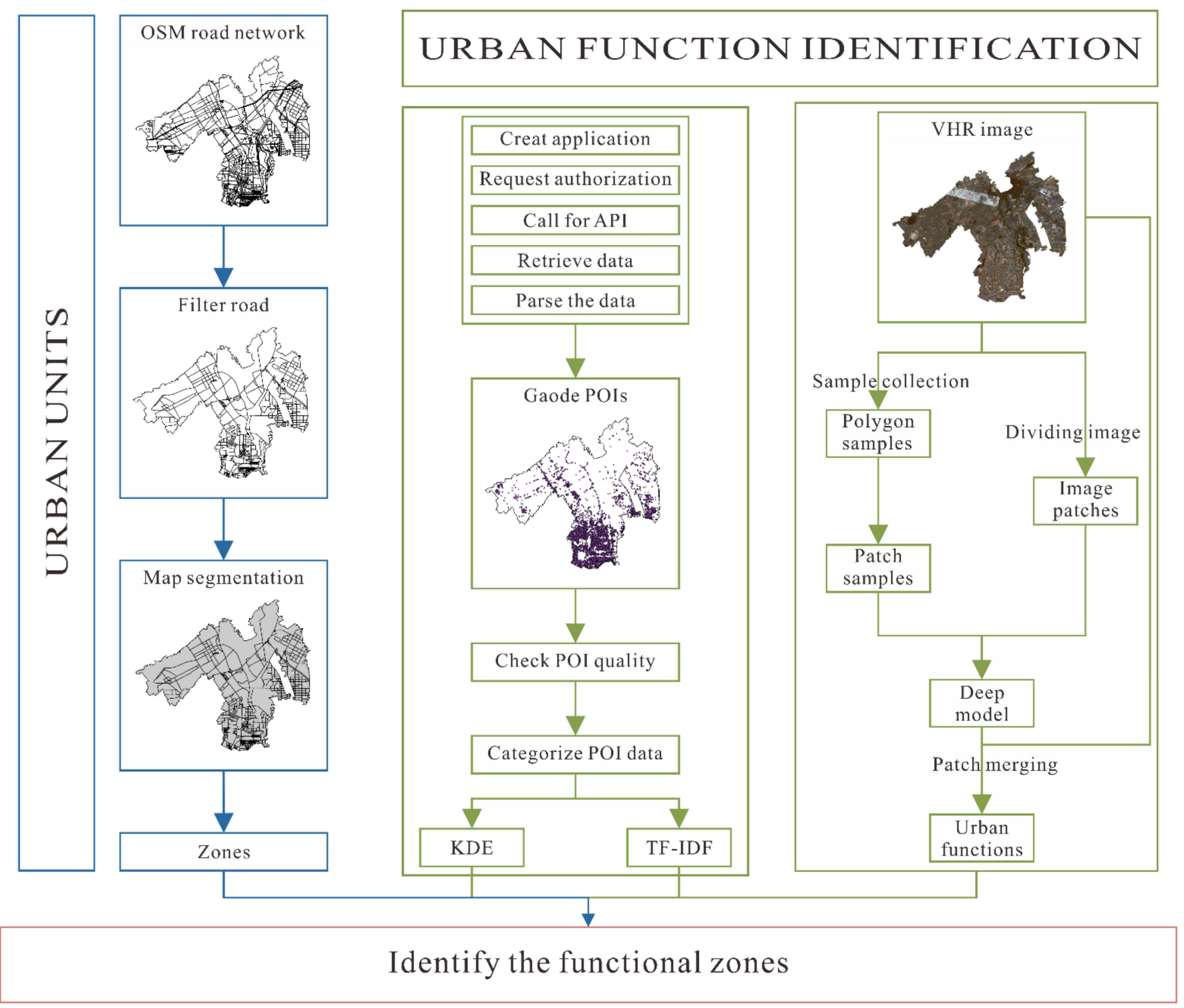

Figure 2. Flowchart of the study.

\subsubsection{Unit Division of Urban Functional Zones}

An urban functional zone is a fundamental unit carrying socioeconomic functions in urban planning and management. The parcel formed by a road network is the basic unit of urban planning and management, and it serves the socioeconomic functions of a city [44]. In this study, road vectors obtained from OSM were used to delineate functional zones, and each zone was spatially represented by a block. First, motorway, motorway_link, primary, primary_link, tertiary, tertiary_link, cycleway, residential, track, and trunk roads 
were selected and topology-processed; this involved extending roads by $100 \mathrm{~m}$ to process unconnected road networks and trimming road networks in suspension roads and separate roads. Then, the road space was created by establishing $20 \mathrm{~m}$ buffer zones for the roads. The space was used to generate a binary road grid image, and then the centerline extraction function under the ArcScan module in ArcGIS 10.4 was used to extract the centerline of the road. After manual correction, urban functional zone units were generated and, after deleting smaller land units, 707 zones were finally generated.

\subsubsection{Classification System}

A city-function zoning system is a division of zones in a city based on dominant functions. It forms a coherent functional aggregation, establishes relatively independent and interconnected functional zones, and forms an organic whole through rational planning. As the base map for territorial spatial planning, the main functional zones provide a common basis for all manner of spatial governance policies, planning, and evaluation [45]. Thus, functional zones, based on the agglomeration of urban elements, are important for the urban functional layout, facilitating the macroscopic specification, coordination, and matching of urban functions.

Researchers have offered various classifications (Table 1) for the urban functional zone, including residential, commercial, ecological, industrial, public, and transport classifications. According to the Code for Classification of Urban Land Use and Planning Standards of Development Land (GB 50137-2011), urban development land includes the following types: residential, administration and public services, commercial and business facilities, industrial, manufacturing, logistics and warehouse, road, street and transportation, municipal utilities, and green space and square. Thus, this study used the following functional classifications, as mentioned previously: RN, CN, PN, IN, and EN. There is no transport zone since zones were divided based on the central line of the roads.

Table 1. Functional zoning classifications by different researchers.

\begin{tabular}{|c|c|c|}
\hline Order & Functional Classifications & Authors \\
\hline 1 & $\begin{array}{c}\text { Diplomatic and political zone, science and education zone, } \\
\text { mature residential zone, new residential zone, commercial and } \\
\text { entertainment zone, tourist attraction zone, area to be developed, } \\
\text { unclassified area }\end{array}$ & Miao et al. [19] \\
\hline 2 & $\begin{array}{l}\text { Commercial zone, campuses, parks and greenbelts, industrial } \\
\text { zone, residential districts, shantytowns }\end{array}$ & Zhang et al. [26] \\
\hline 3 & $\begin{array}{c}\text { Corporate business area or factory, shopping mall, tourism } \\
\text { attraction place, public facility, transportation facility, science and } \\
\text { education place, medical service place, food and beverage place } \\
\text { and daily life service place, governmental and } \\
\text { public organizations }\end{array}$ & Hu et al. [20] \\
\hline 4 & $\begin{array}{l}\text { Residential, education and training, recreation and entertainment, } \\
\text { medical and public health, commercial and finance, incorporated } \\
\text { and business, party and government organization, scenic areas }\end{array}$ & Luo et al. [46] \\
\hline 5 & $\begin{array}{l}\text { Office building/space, financial services, medical/education, } \\
\text { entertainment, life services, residence communities, government }\end{array}$ & Hong and Yao [21] \\
\hline 6 & $\begin{array}{c}\text { Ecological area, transit region, urban buffer, suburbs, subcenter, } \\
\text { urban center }\end{array}$ & Tu et al. [25] \\
\hline 7 & $\begin{array}{l}\text { Urban green, industrial districts, public services, residential } \\
\text { districts, commercial districts, hospitals, schools, shantytowns }\end{array}$ & Bao et al. [36] \\
\hline 8 & $\begin{array}{l}\text { Developed working and industrial regions, developed public } \\
\text { service region, emerging working and industrial regions, } \\
\text { emerging residential region, developed residential region, nature } \\
\text { park, developing rural region, undefined region }\end{array}$ & Zhai et al. [40] \\
\hline 9 & Mixed use, residential, industry, business, conservation & Malik and Dewancker [47] \\
\hline
\end{tabular}

\subsubsection{U-Net Deep Learning}

U-Net was first proposed for biomedical image segmentation [48]. Given the advantages of its simple, effective symmetrical encoder-decoder structure, U-Net has been widely used for various remote-sensing tasks, such as semantic segmentation. Most researchers use the U-Net framework or an improved version of it. ResUNet-a is a U-Net-based 
deep learning architecture that can improve the semantic segmentation of high-resolution remote-sensing images [35]. Peng et al. [49] proposed UNet++ for semantic segmentation based on the encoder-decoder architecture. He et al. [50] proposed HFSA-Unet to explore the correlations among the immediate layers for automatic building segmentation in remote-sensing images.

Therefore, we chose U-Net to classify urban functional zones. The architecture of U-Net can be thought of as an encoder network followed by a decoder network. Unlike a classification, where the end result of the deep network is the only important thing, semantic segmentation requires not only pixel-level discrimination but also a mechanism to project the discriminative features learned at different stages of the encoder onto the pixel space.

The encoder is the first half of the architecture diagram (Figure 3). It is usually a pre-trained classification network, such as VGG/ResNet, where convolution blocks are applied, followed by max pool downsampling to encode the input image into feature representations at multiple levels. The decoder is the second half of the architecture. The goal is to semantically project the discriminative features (lower resolution) learned by the encoder onto the pixel space (higher resolution) to get a dense classification. The decoder consists of upsampling and concatenation, followed by regular convolution operations.
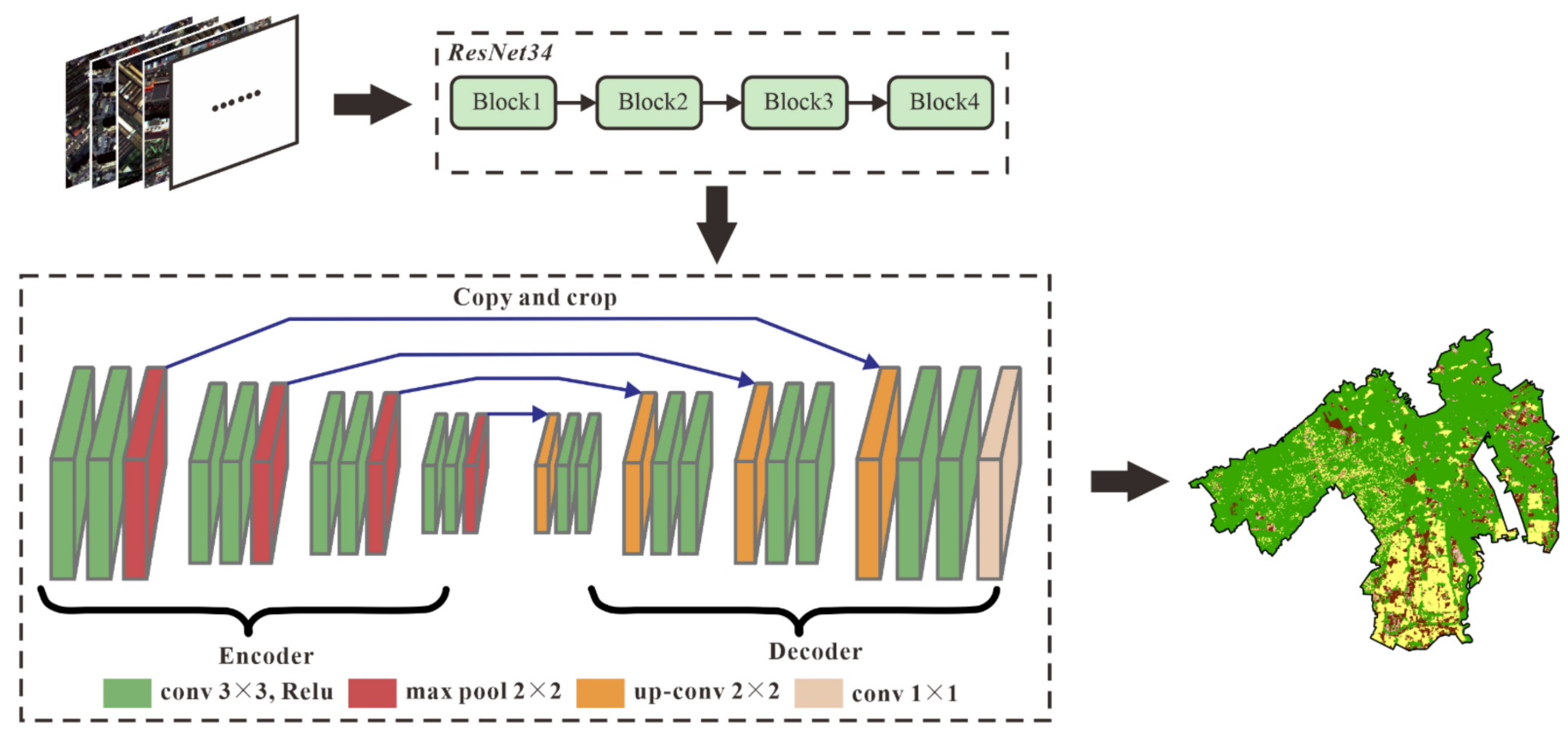

Figure 3. U-Net architecture.

U-Net is a classification method with supervised learning; thus, the samples, which are fundamental for recognizing zone functions, should be selected first. We used fieldwork information for $25 \mathrm{~km}^{2}$ of urban area in the Kuancheng District for sampling. This area stretches from rural-urban fringe areas to urban areas and includes all urban functional types. The function "Label Objects for Deep Learning" under "Classification Tools" in ArcGIS Pro 2.7 was used to export the training data. Metadata were formatted as "Classified Tiles" so we could train the U-Net model.

The training model was implemented in the PyCharm development environment using Python so that more details could be identified, and some parameters could be adjusted and optimized. Finally, the function "Classify Pixels Using Deep Learning" under "Image Analyst" in ArcGIS Pro 2.7 was used to identify the urban functional zones.

The function of each zone was determined by the area proportions of different functional areas in the zones. A type ratio of $50 \%$ was selected as the functional zone standard. When a type of area proportion reached $50 \%$ or more in the unit, it was considered a single 
functional zone. When all area proportions were less than $50 \%$, it was considered a mixed functional zone, which was determined by the two main types in the unit, whose area proportions were between $30 \%$ and 50\%. When all area proportions were greater than $0 \%$ but less than $30 \%$, it was considered a mixed uniform functional zone. When all area proportions were 0 , it was considered a no data zone.

\subsubsection{Verification}

The accuracy of KDE, UDL, and TF-IDF was assessed against the field survey data using confusion matrices, which was summarized to provide further accurate information by computing quantity disagreement, shift disagreement, and exchange disagreement [51]. Quantity disagreement is the difference between the prediction and field survey categories due to an imperfect match in the overall proportions of all mapped categories. Shift and exchange are allocation disagreements which are the difference between the field survey and the prediction due to an imperfect match in the spatial allocations of the mapped categories, given the categorical proportions in the field survey and prediction [52]. Exchange is the disagreement of allocation disagreement that pairwise confusions cause, and shift is the disagreement that non-pairwise confusions cause [52].

\section{Results}

3.1. Identification of Functional Zones

3.1.1. Single Functional Zone

Kuancheng District can be divided into five single functional zones. Figure 4 shows the distribution of single functional zones in the study area based on the methods of KDE (Figure 4a), UDL (Figure 4b), and TF-IDF (Figure 4c).

KDE, TF-IDF, and UDL identified, respectively, 359, 640, and 635 single functional zones. In the KDE results, IN accounted for the largest number (190 zones). The number of single functional zones gradually increased in the following order: CN, EN, NN, and RN. Except for the southern part of the Kuancheng District, which is close to the city center, most single functional zones were spread out across the region.

In the TF-IDF results, CN accounted for the largest number (295 zones). The number of single functional zones gradually increased in the following order: RN, EN, PN, IN, and NN. Single functional zones were evenly distributed in Kuancheng District.

In the UDL results, RN accounted for the largest number (300 zones). The number of single functional zones gradually increased in the following order: PN, NN, IN, and EN. The single functional zone for $\mathrm{CN}$ was zero. This indicates that either $\mathrm{CN}$ and others became mixed functional areas or CN was not identified by the UDL method. Single functional zones were evenly distributed in the study area.

\subsubsection{Mixed Functional Zones}

Figure 5 shows the spatial distribution of mixed functional zones in the Kuancheng District; the colors indicate different mixed functional zones. Table 2 shows the results. The horizontal axis is the largest of the functional areas in the zone, and the vertical axis is the second-largest, which determines what kind of mixed functional zones the mixed zone contains.

The KDE results included 16 types of mixed functional zones, among which the number of PN-CN zones (54 zones) was the largest, followed by IN-CN (43 zones), CNIN (41 zones), and PN-IN (32 zones). The TF-IDF results contained ten types of mixed functional zones, among which the number of CN-PN zones (22 zones) was the largest, followed by PN-CN (16 zones). The UDL results had the fewest types (eight types) of mixed functional zones, among which the largest were EN-IN (16 zones) and IN-EN (15 zones), followed by RN-EN (11 zones) and RN-IN (10 zones). 

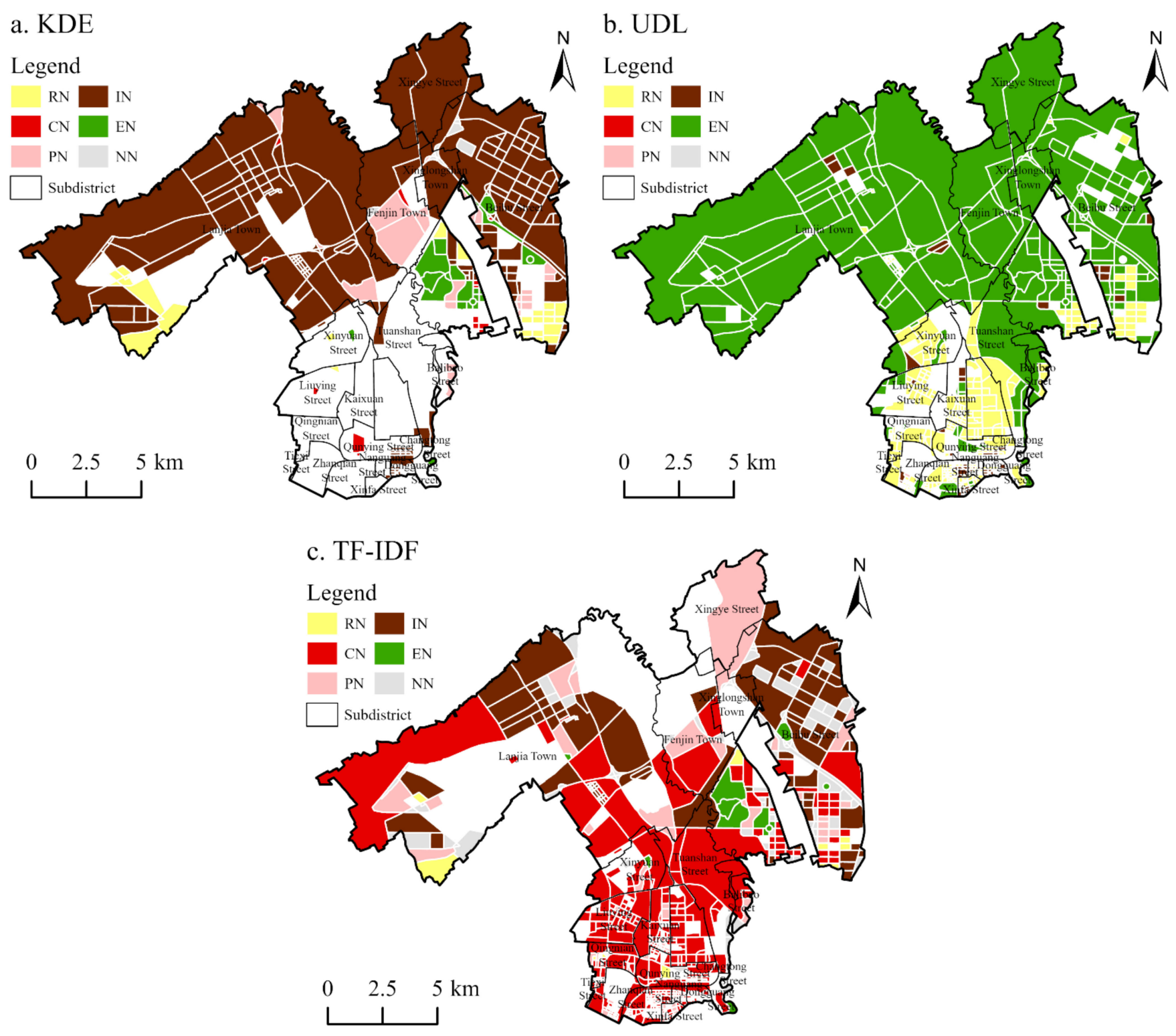

Figure 4. Spatial distribution of single functional zones in Kuancheng District predicted by (a) Size KDE, (b) UDL, and (c) TF-IDF (RN, residential zone; CN, commercial and commercial services facilities zone; PN, public government and public service zone; IN, industrial and mining storage zone; EN, ecological zone; NN, no data zone).

\subsection{Verification}

We evaluated the KDE, TF-IDF, and UDL results as described below. Table 3 shows the results; the horizontal axis is the field survey results, and the vertical axis is the predicted results of three methods.

The overall error for KDE of urban functional zones was $83 \%$, divided between quantity disagreement (66\%), exchange $(9 \%)$, and shift (9\%) (Figure 6). MN had the highest overall error, followed by RN. RN, IN, EN, and MN extended beyond the Quantity Overall line (Figure 7), which indicated that these types had more intensive quantity disagreements relative to the quantity disagreement overall. The intensity of exchange overall is the difference between the Quantity Overall line and the Quantity + Exchange Overall line. PN and IN had more intensive exchange relative to exchange overall, while EN had exchange equal in intensity to exchange overall. The Quantity + Exchange Overall of $89 \%$ implied that the intensity of Shift Overall was $11 \%$, meaning $100 \%$ minus $89 \%$ (Figure 7 ). The shift intensity for $\mathrm{CN}, \mathrm{PN}$, and $\mathrm{NN}$ is entirely to the left of the Quantity + Exchange Overall line; 
therefore, $\mathrm{CN}, \mathrm{PN}$, and $\mathrm{NN}$ had a more intensive shift relative to shift overall. $\mathrm{NN}$ had a shift equal in intensity to shift overall.

a. KDE

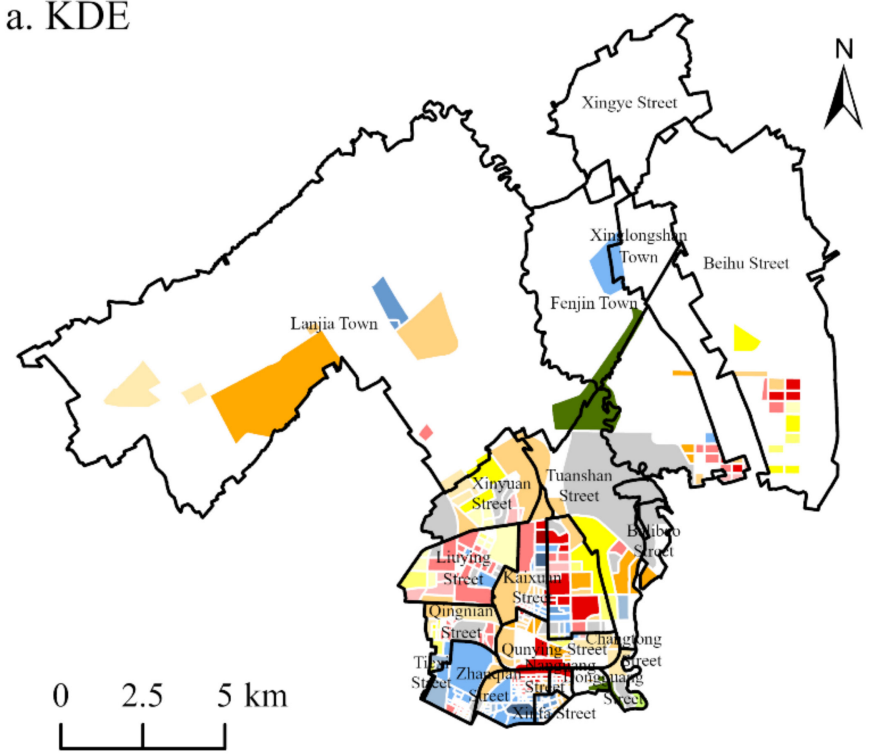

c. TF-IDF

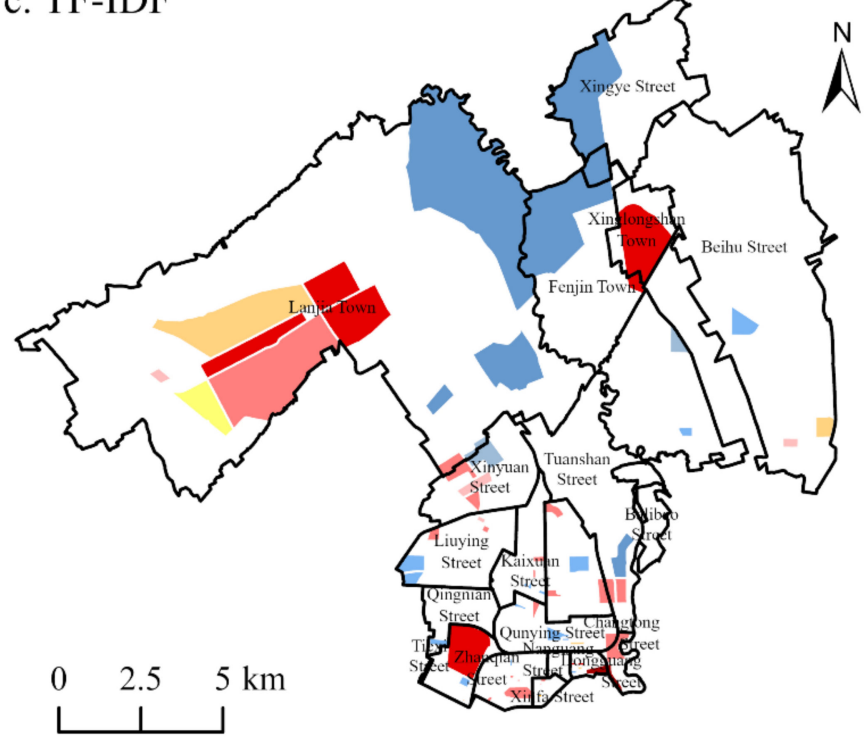

b. UDL

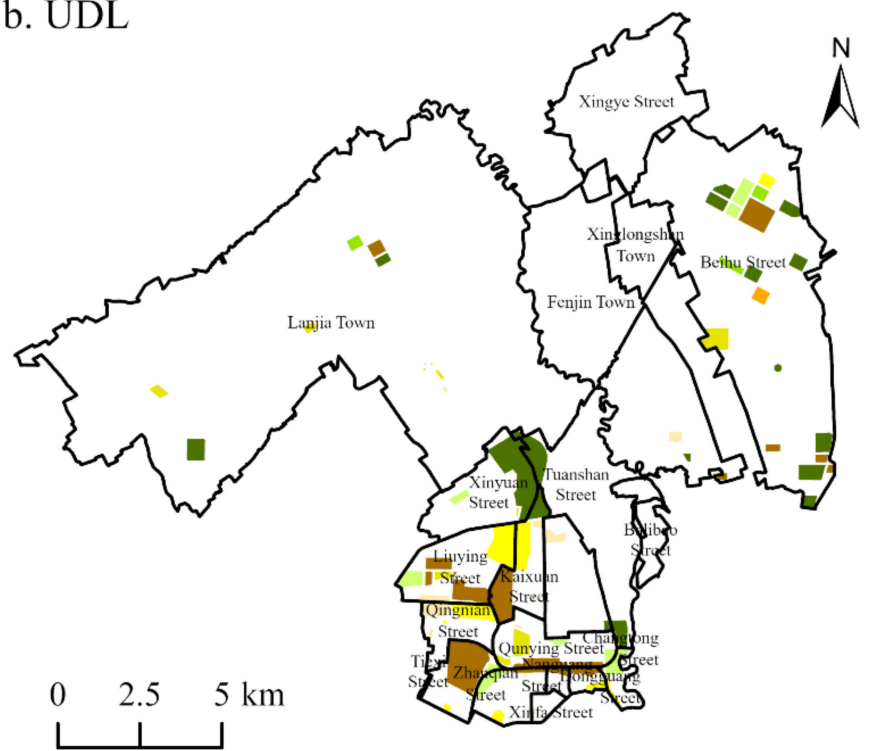

Legend

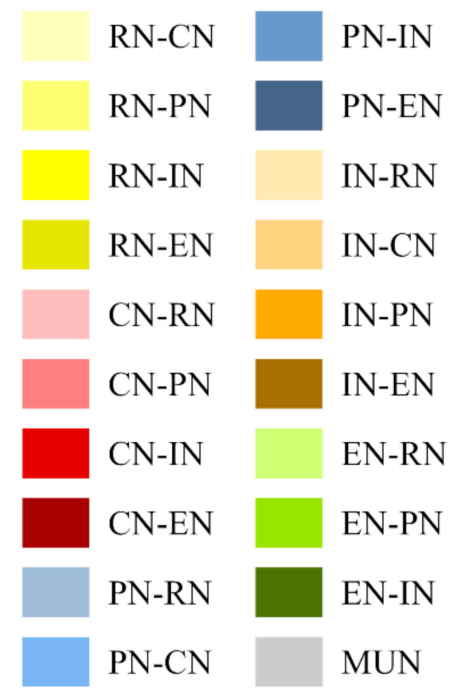

Figure 5. Spatial distribution of mixed functional zones in Kuancheng District predicted by (a) Size KDE, (b) UDL, and (c) TF-IDF.

The overall error for TF-IDF of urban functional zones was $71 \%$, divided between quantity disagreement (57\%), exchange (6\%), and shift (8\%) (Figure 6). EN and NN had the highest overall error, and RN, CN, EN, and MN had more intensive quantity disagreements relative to the quantity disagreement overall. Only $\mathrm{MN}$ had a quantity component less intensive than the intensity of the overall quantity component. PN, IN, and MN had more intensive exchange relative to exchange overall, and PN, IN, and MN had a more intensive shift relative to shift overall.

The overall error for UDL of urban functional zones was $43 \%$, divided between quantity disagreement $(21 \%)$, exchange $(11 \%)$, and shift $(10 \%)$ (Figure 6$)$. EN had the highest overall error, followed by RN and MN. CN, PN, EN, and NN had more intensive quantity disagreements relative to quantity disagreement overall. RN and $\mathrm{MN}$ had more intensive exchange relative to exchange overall, while IN had exchange equal in intensity 
to exchange overall. $\mathrm{RN}$, IN, and $\mathrm{MN}$ had a more intensive shift relative to shift overall. Besides, $\mathrm{CN}$ and $\mathrm{NN}$ had no exchange and shift disagreements.

Table 2. Confusion matrix of functional zones where diagonal number is the number of single functional zones, and the other number is the mixed functional zones.

\begin{tabular}{|c|c|c|c|c|c|c|c|c|c|}
\hline \multicolumn{10}{|c|}{ The Largest Functional Area } \\
\hline \multirow{28}{*}{ 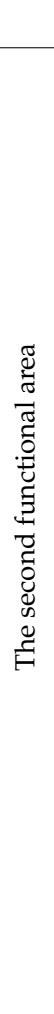 } & & RN & $\mathrm{CN}$ & PN & IN & EN & MUN & NN & Total \\
\hline & & & & & a. KD & & & & \\
\hline & RN & 30 & 19 & 10 & 10 & 1 & & & 70 \\
\hline & $\mathrm{CN}$ & 12 & 16 & 54 & 43 & & & & 125 \\
\hline & PN & 12 & 72 & 28 & 24 & & & & 136 \\
\hline & IN & 9 & 41 & 32 & 190 & 3 & & & 275 \\
\hline & EN & & 1 & 3 & 2 & 26 & & & 32 \\
\hline & MUN & & & & & & 40 & & 40 \\
\hline & NN & & & & & & & 29 & 29 \\
\hline & Total & 63 & 149 & 127 & 269 & 30 & 40 & 29 & 707 \\
\hline & & & & & TF-II & & & & \\
\hline & RN & 11 & 5 & 3 & & & & & 19 \\
\hline & $\mathrm{CN}$ & & 295 & 16 & 4 & & & & 315 \\
\hline & PN & 1 & 22 & 77 & 2 & & & & 102 \\
\hline & IN & & 8 & 4 & 83 & & & & 95 \\
\hline & EN & & 2 & & & 16 & & & 18 \\
\hline & MUN & & & & & & & & \\
\hline & NN & & & & & & & 158 & 158 \\
\hline & Total & 12 & 332 & 100 & 89 & 16 & & 158 & 707 \\
\hline & & & & & c. UD & & & & \\
\hline & $\mathrm{RN}$ & 300 & & & 7 & 9 & & & 316 \\
\hline & $\mathrm{CN}$ & & & & & & & & \\
\hline & PN & & & 2 & 1 & 3 & & & 6 \\
\hline & IN & 10 & & & 67 & 16 & & & 93 \\
\hline & EN & 11 & & & 15 & 264 & & & 290 \\
\hline & MUN & & & & & & & & \\
\hline & NN & & & & & & & 2 & 2 \\
\hline & Total & 321 & & 2 & 90 & 292 & & 2 & 707 \\
\hline
\end{tabular}

Note: RN, residential zone; CN, commercial and commercial services facilities zone; PN, public government and public service zone; IN, industrial and mining storage zone; EN, ecological zone; MUN, mixed uniform functional zone; NN, no data zone; KDE, kernel density estimation; TF-IDF, term frequency-inverse document frequency; UDL, U-Net deep learning.

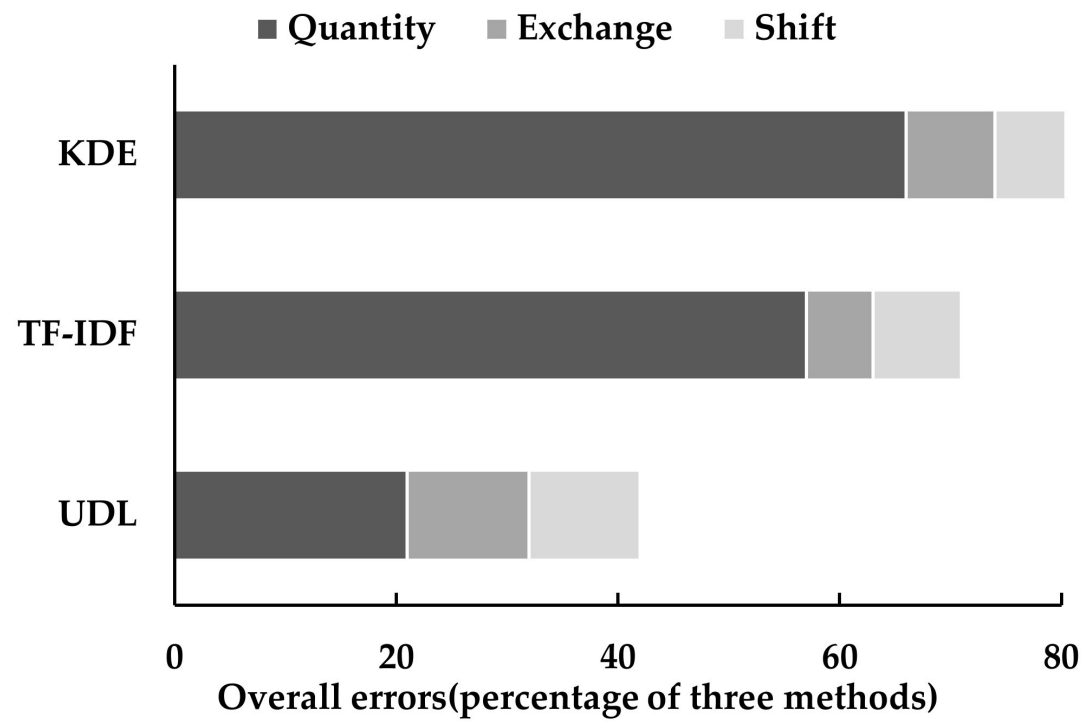

Figure 6. Overall errors of three methods. 
Table 3. Verification confusion matrix of functional zones.

\begin{tabular}{|c|c|c|c|c|c|c|c|c|c|c|}
\hline \multicolumn{11}{|c|}{ Field Survey Data } \\
\hline & & RN & $\mathrm{CN}$ & PN & IN & EN & MN & $\mathbf{N N}$ & ON & Total \\
\hline \multirow{26}{*}{ 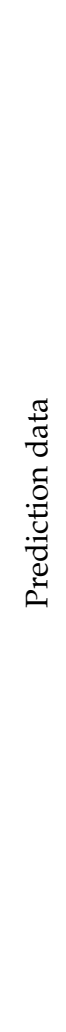 } & \multicolumn{10}{|c|}{ a. KDE } \\
\hline & $\mathrm{RN}$ & 17 & & & 3 & 9 & 1 & & & 30 \\
\hline & $\mathrm{CN}$ & 7 & & 2 & & 5 & 1 & 1 & & 16 \\
\hline & $\mathrm{PN}$ & 3 & 2 & 1 & 1 & 15 & 3 & 3 & & 28 \\
\hline & IN & 22 & 21 & 6 & 39 & 68 & 24 & 10 & & 190 \\
\hline & $\mathrm{EN}$ & 1 & 2 & 2 & 1 & 19 & & & 1 & 26 \\
\hline & $\mathrm{MN}$ & 236 & 43 & 34 & 9 & 31 & 29 & 6 & & 388 \\
\hline & NN & & & & 1 & 10 & & 18 & & 29 \\
\hline & Total & 286 & 68 & 45 & 54 & 157 & 58 & 38 & 1 & 707 \\
\hline & \multicolumn{10}{|c|}{ b. TF-IDF } \\
\hline & & 9 & & & & 2 & & & & 11 \\
\hline & $\mathrm{CN}$ & 199 & 35 & 11 & 8 & 16 & 25 & & 1 & 295 \\
\hline & $\mathrm{PN}$ & 26 & 8 & 17 & 3 & 15 & 8 & & & 77 \\
\hline & IN & 3 & 13 & 3 & 31 & 25 & 8 & & & 83 \\
\hline & $\mathrm{EN}$ & & 2 & 2 & & 12 & & & & 16 \\
\hline & $\mathrm{MN}$ & 33 & 3 & 5 & 3 & 12 & 11 & & & 67 \\
\hline & $\mathrm{NN}$ & 16 & 7 & 7 & 9 & 75 & 6 & 38 & & 158 \\
\hline & Total & 286 & 68 & 45 & 54 & 157 & 58 & 38 & 1 & 707 \\
\hline & \multicolumn{10}{|c|}{ c. UDL } \\
\hline & $\mathrm{RN}$ & 233 & 27 & 14 & 4 & 8 & 13 & 1 & & 300 \\
\hline & $\mathrm{PN}$ & & & 1 & 1 & & & & & 2 \\
\hline & IN & 13 & 19 & 13 & 12 & 2 & 8 & & & 67 \\
\hline & $\mathrm{EN}$ & 27 & 12 & 11 & 12 & 143 & 23 & 35 & 1 & 264 \\
\hline & $\mathrm{MN}$ & 13 & 10 & 6 & 25 & 4 & 14 & & & 72 \\
\hline & $\mathrm{NN}$ & & & & & & & 2 & & 2 \\
\hline & Total & 286 & 68 & 45 & 54 & 157 & 58 & 38 & 1 & 707 \\
\hline
\end{tabular}
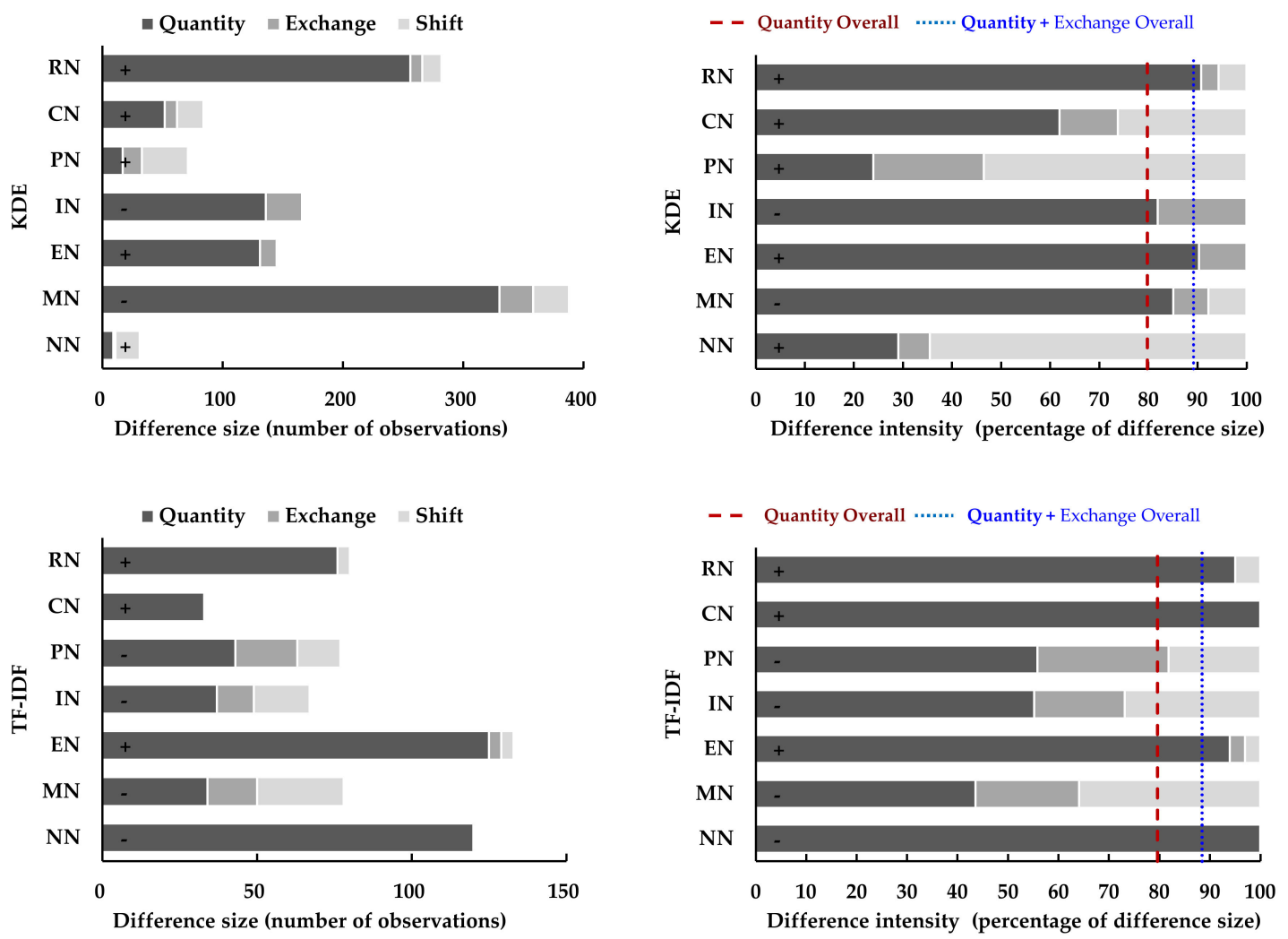

Figure 7. Cont. 

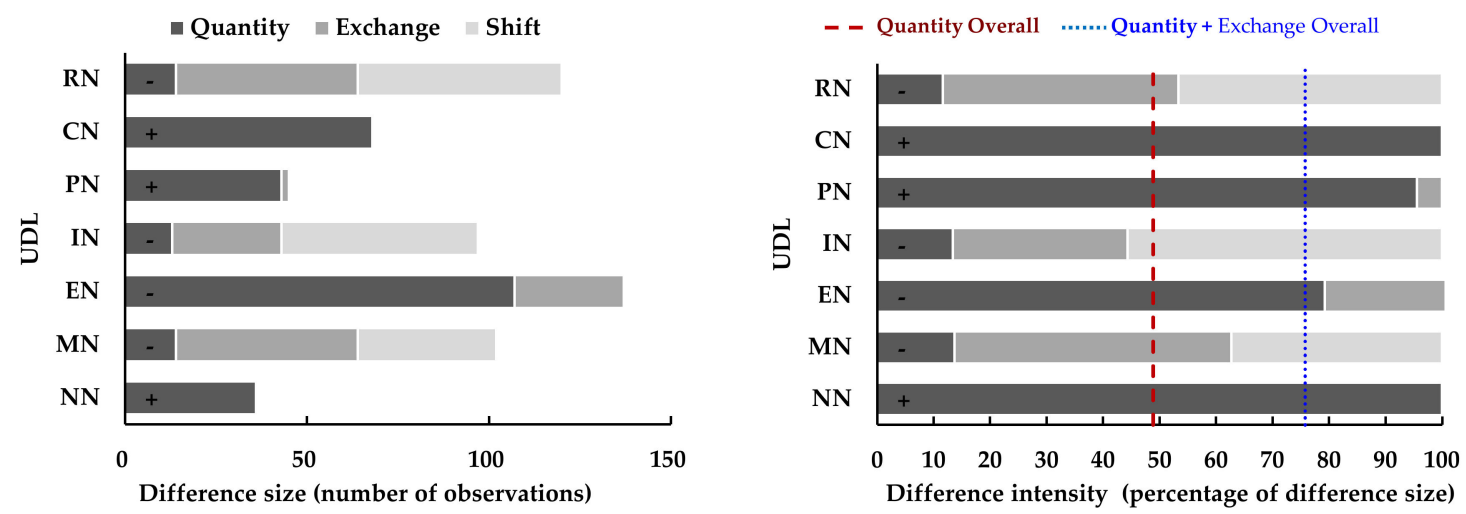

Figure 7. (left) Size and (right) intensity of differences for Table 3. A positive sign in the quantity disagreement denotes the number of the functional zones in a prediction is greater than in the field survey; a negative sign denotes the number of the functional zones in a prediction is less than in the field survey.

Figure 8 shows the spatial distribution of the prediction results of KDE, TF-IDF, and UDL with field surveys. The KDE results had more IN zones, especially in Lanjia Town, Beihu Street, and Xingye Street. The reason could be that there are many industrial or storage POIs but few other POI types. Therefore, the distribution of POIs in suburban and rural areas may have reduced the accuracy of identification.

The TF-IDF results identified more CNs than in the field survey, and the distribution of different functions was not very accurate. This is because in TF-IDF, the smaller the text frequency (i.e., the number of texts containing a certain word) of a word, the greater its ability to distinguish between different categories of text. If one functional type is in every zone, its IDF is zero; so, TF-IDF thinks it is a noise word, leading to an incorrect result. Thus, TF-IDF is minimally effective for special functional zones.

The UDL results were the most accurate, showing almost the same distribution as the field survey, except for CN. There were no CNs in the UDL results, although commercial and financial land existed in the field survey. This is because there were few CNs in the sampling area, which could be used as samples, making it difficult to identify them through remote sensing.

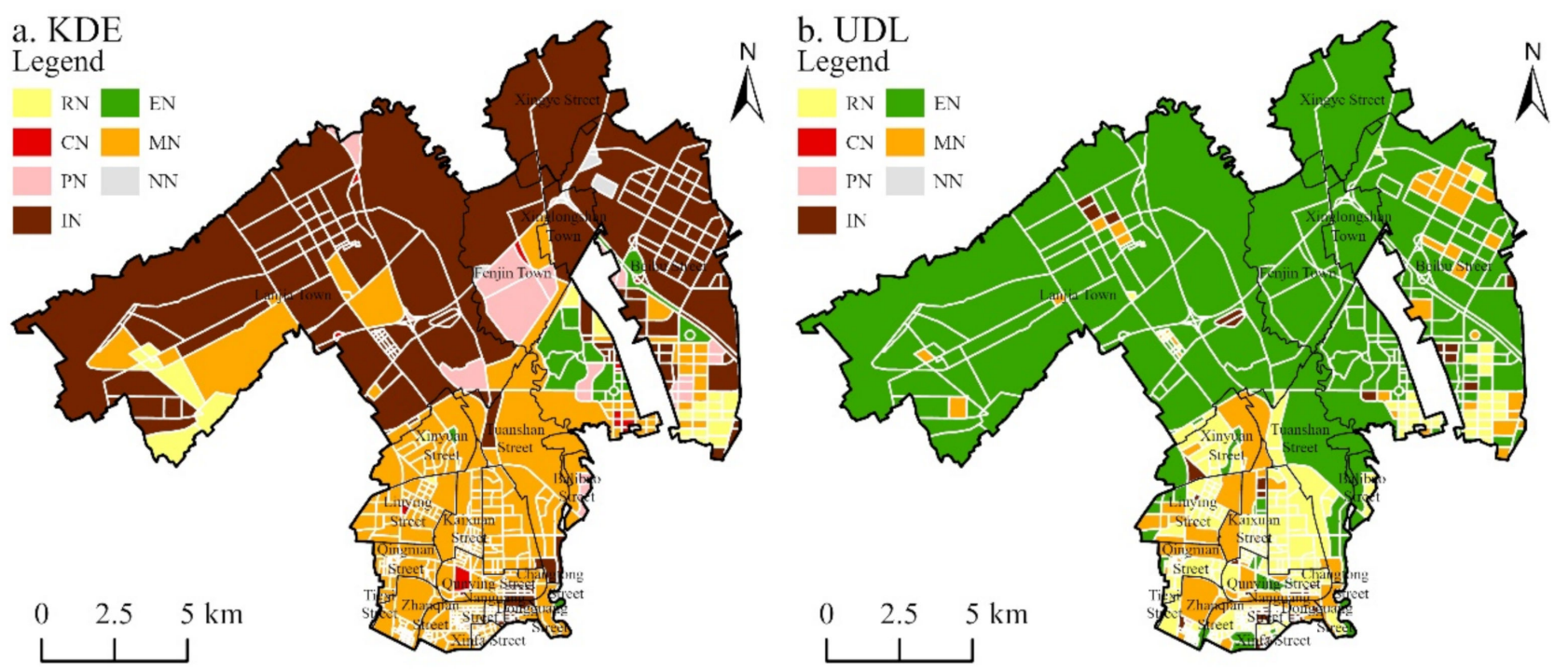

Figure 8. Cont. 

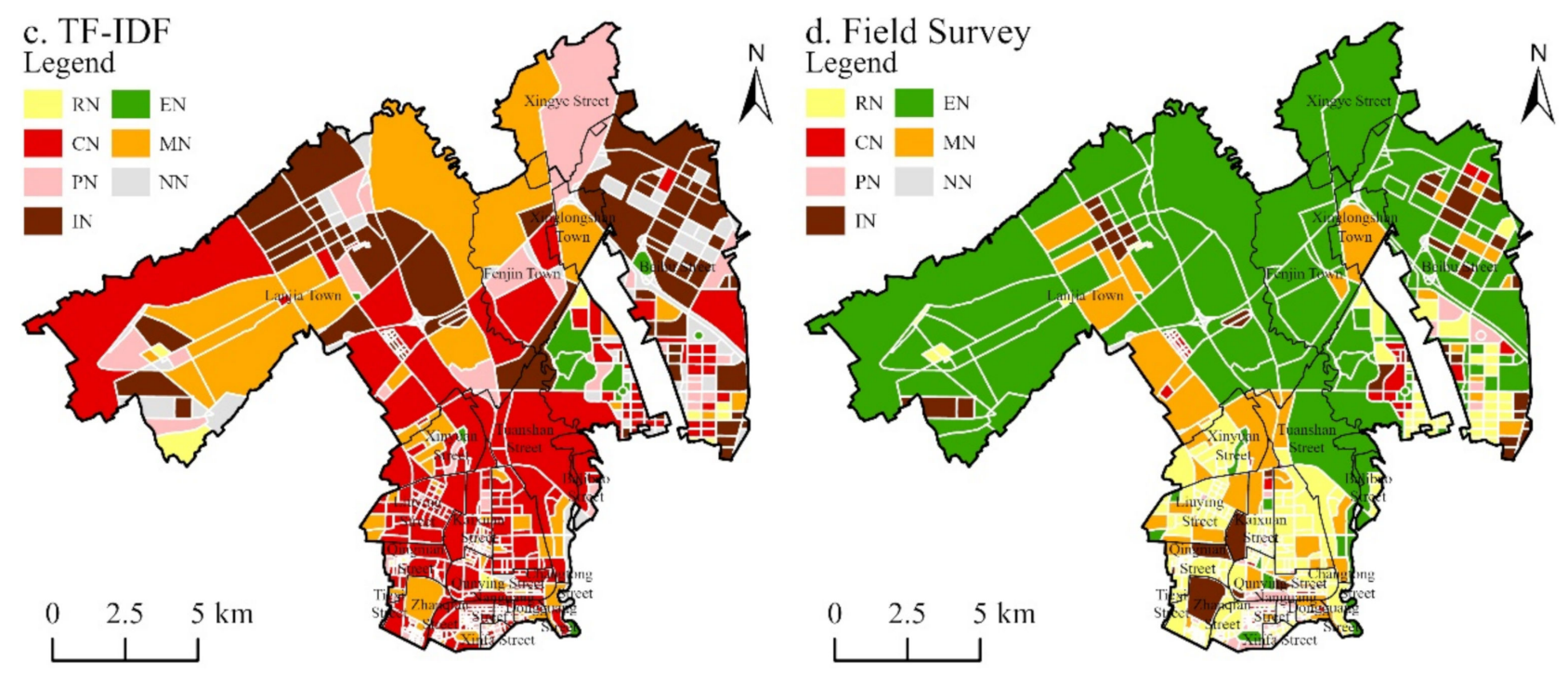

Figure 8. Spatial distribution of the prediction results of (a) KDE, (b) TF-IDF, and (c) UDL, with (d) field surveys.

Figure 9 shows the comparison of the UDL and the field survey results. The different functional zone (237) results of UDL and the field survey are mainly distributed in Zhanqian Street, Xinfa Street, and Dongguang Street, which are urban central areas. There are also some in Beihu Street, which is part of Changchun's new district. The functional zones, where there are overlaps of functional types (74), are distributed in all the streets within Kuancheng Street, except Balibao Street, Nanguang Street, and Xingye Street. Identical functional types (396) are mainly distributed in Lanjia Town, Fenjin Town, Xinghongshan Town, Xingye Street, north of Tuanshan Street, and west of Beihu Street, which are urban and rural zones.
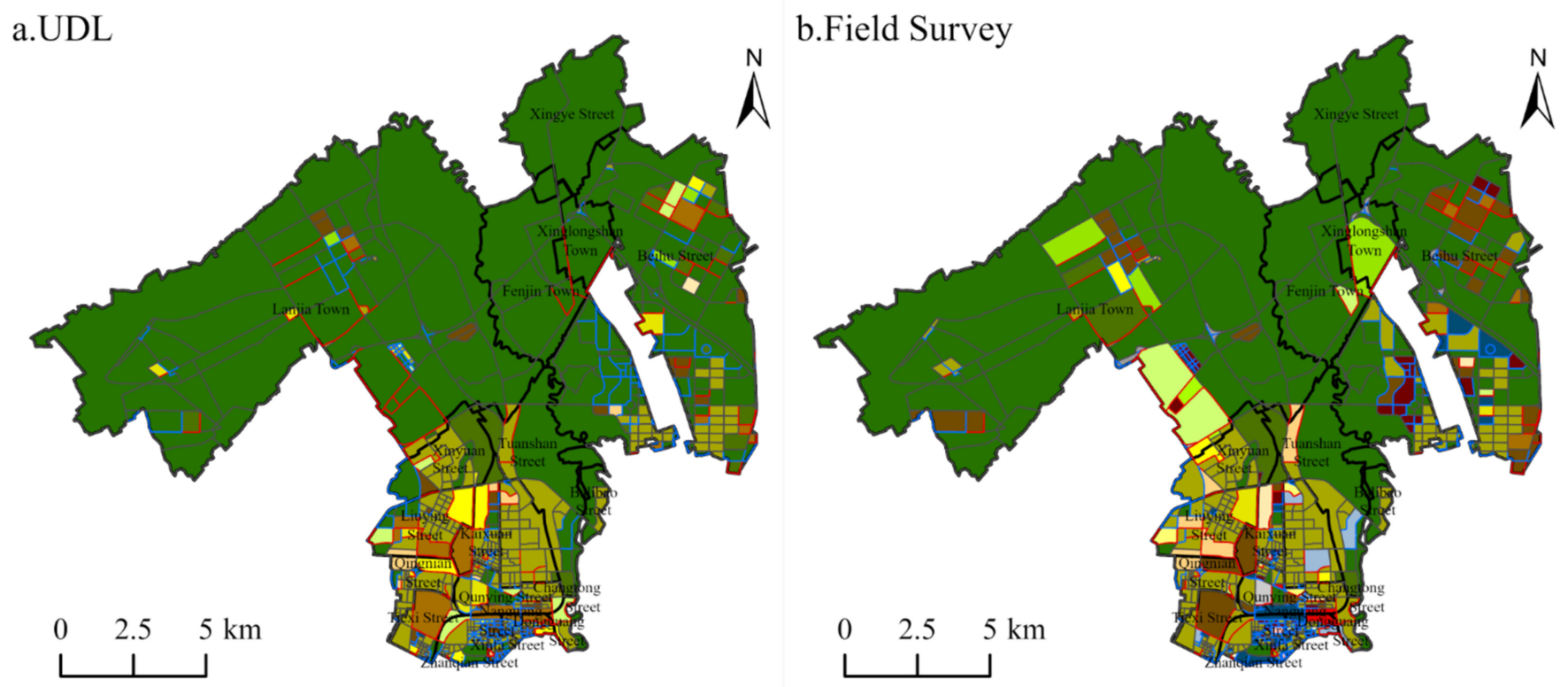

Legend
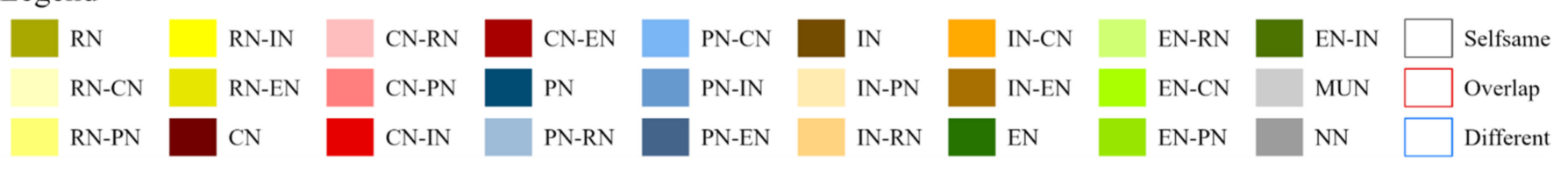

Figure 9. Comparison of (a) UDL and (b) field survey results. 


\subsection{Spatial Pattern of Urban Functional Zones}

Kuancheng District is north of Changchun (Figure 10). EN is the largest functional classification area; it is found mostly in peri-urban regions, with many forests and cultivated lands. $\mathrm{RN}$ is concentrated in the southern part of Kuancheng, close to Changchun's city center. There are also a few RNs in the northern region since there is some rural residential land there. RNs are mainly distributed in Lanjia Town and Beihu Street, with a small amount distributed on Zhanqian Street and the intersection of Liuying Street, Kaixuan Street, and Qingnian. Most PNs and CNs are located in the southern region, especially in the city center, while RNs are scattered throughout the study area.

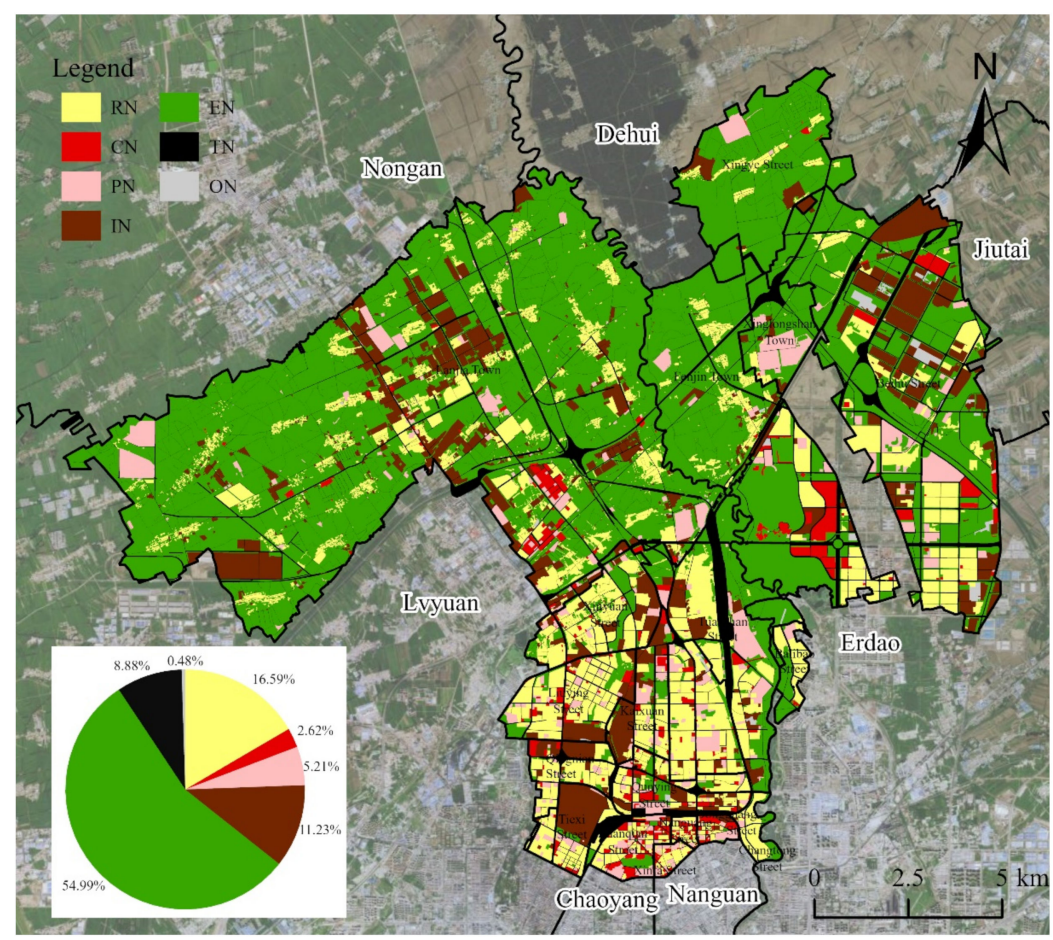

Figure 10. Spatial distribution of the urban functional classifications of Kuancheng District.

In general, Kuancheng District forms three development zones. The southern development area is a comprehensive area of the district's main functions. The eastern development area, composed of urban industrial areas and ecological wetland, is the main expansion area for future land development. The western development area is a compound area of industrial and agricultural township development, where the function of Lanjia Town is mainly industrial, supplemented by residential functions.

\section{Discussion}

\subsection{Development Current Situation}

Kuancheng District, Fenjin Town, and Beihu Street, which belong to the Northeast China Development Open Pilot Area of Changchun, are rapidly expanding urban-rural transition zones. A reasonable layout of functional zones is conducive to the coordinated development of urban and rural areas. This region will be a major expansion space for the future development of the Kuancheng District. It is therefore of great significance for Changchun's sustainable development and will provide an effective reference for establishing land-use planning to scientifically design urban functional layouts. Overall, Kuancheng District is progressing toward achieving the goals of the Land-Use Plan of the Central City of Changchun (2011-2020) (Figure 11), indicating that the plan has had practical instructive significance. 

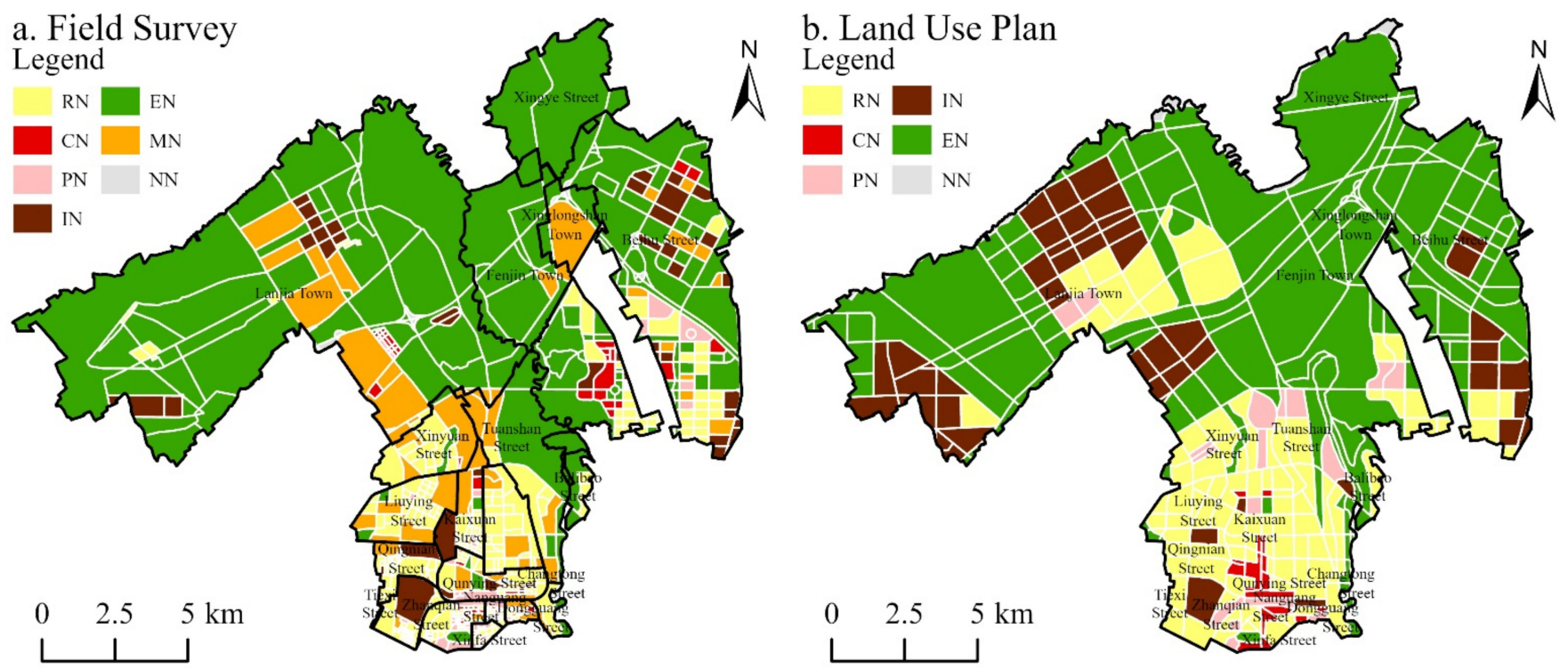

Figure 11. Comparison of (a) field survey and (b) land-use plan.

\subsection{Comparison with Exiting Studies}

Many studies have attempted to produce urban functional zone maps using remotesensing images and POI data. Here, we compare our study with several previous studies in terms of data sources, study area, and methods (Table 4). First, regarding data sources, the distribution and number of points of interest have some effects. POI data are points of different activities, such as shopping, working, studying, and dining, which reflect people's preferences and social functions [53]. Although POI data provides good semantic information, there is a greater concentration of POIs near areas that have a high population density [26] because POIs are associated with people's activities. There are fewer POIs in suburban or rural areas, which may lead to a lower level of accuracy for identifying urban functional zones. In addition, there may be many small shops, restaurants, barbershops, public baths, and other service functions scattered around residential areas, whose distributions are more intensive than residential distributions. This could have an adverse effect on the identification results for functional zones. Apart from POI data, vector data from OSM also contains geospatial semantics for its geo-objects [54] and can also provide semantics for urban functional zones.

As for remote sensing, in submeter-level high-resolution images, ground object types are more diverse, texture types and regions are significantly increased, and texture features are more variable. They are, however, more expensive. Although medium-resolution images are easy to acquire and can cover large spatial areas, it is difficult to produce fine-grained urban functional zones based on them because of their lower spatial resolution [55]. The cost and spatial resolution of meter-level high-resolution images range between the two. Therefore, many aspects should be considered in remote-sensing image selection. Compared with only using remote-sensing images, adding semantic information to remote-sensing images has higher classification accuracy. Urban functional zones composed of various geographic objects (such as buildings, roads, and vegetation) [55] are regions with unified functions, relatively independent and connected with each other, and constituting an organic whole with a reasonable layout. As buildings in the city are divided by roads, urban functional zones have a close relation to the regions formed by the city road network [21]. Moreover, the fixed-size grid division method destroys the integrity of the land use pattern [55], so the division of units by road network is more consistent with the definition and scope of the urban functional area than the grid. However, if the study area is large (such as a country), the larger size of the grid partition performs better macroscopically [56]. 
Table 4. Comparison with existing studies.

\begin{tabular}{|c|c|c|c|c|}
\hline Authors & $\begin{array}{l}\text { Data } \\
\text { Source }\end{array}$ & Study Area & Mapping Unit & Methods \\
\hline Xin et al. [6] & $\begin{array}{l}\text { MHRI } \\
\text { SHRI }\end{array}$ & Beijing and Wuhan & Roads & $\begin{array}{l}\text { BOVW (bag of visual word) } \\
\text { model and SDA } \\
\text { (semi-supervised discriminant } \\
\text { analysis) dimensionality } \\
\text { reduction approach }\end{array}$ \\
\hline Du et al. [55] & MHRI & $\begin{array}{l}\text { Beijing and } \\
\text { Shanghai }\end{array}$ & Objects & $\begin{array}{l}\text { Multi-scale semantic } \\
\text { segmentation network }\end{array}$ \\
\hline Heiden et al. [12] & MHRI & Munich & Pixels & $\begin{array}{l}\text { Automated multi-stage } \\
\text { processing system }\end{array}$ \\
\hline Myint et al. [13] & SHRI & Phoenix, Arizona & Objects & Object-based classifier \\
\hline Chen et al. [14] & MPPD & $\begin{array}{l}\text { Yuexiu District, } \\
\text { Guangzhou }\end{array}$ & Buildings & Improved k-medoids method \\
\hline Du et al. [22] & $\begin{array}{l}\text { MHRI } \\
\text { POI }\end{array}$ & $\begin{array}{l}\text { Three districts in } \\
\text { Beijing }\end{array}$ & Roads & LDA, SVM \\
\hline Hong and Yao [21] & POI & Guangzhou & Roads & $\begin{array}{l}\text { Infomap community } \\
\text { detection algorithm }\end{array}$ \\
\hline This study & $\begin{array}{l}\text { SHRI } \\
\text { POI }\end{array}$ & $\begin{array}{l}\text { Kuancheng } \\
\text { District, } \\
\text { Changchun }\end{array}$ & Roads & UDL, KDE, TF-IDF \\
\hline
\end{tabular}

Note: SHRI: submeter-level high-resolution images; MHRI: meter-level high-resolution images; MPPD: mobile phone positioning data; POI: point of interest.

This study identified urban functional zones with POIs and GF-2 images using three methods: KDE, TF-IDF, and UDL. We first consider the limitations of KDE. Different bandwidths affect the results $[18,57,58]$. When the bandwidth is small, details can be detected, and a finer mesh density estimate can be obtained, while a larger bandwidth produces a smoother distribution and is suitable for the overall analysis [58]. In this study, 500 was chosen as the bandwidth for KDE, which was determined by the functional areas. It will be necessary to conduct further research to compare the effects of different bandwidths. TF-IDF is a natural language processing method that cannot explain how one spatial point is determined by its surroundings [40]. In this study, TF-IDF performed poorly in identifying urban functional zones because it only considered distribution frequency and ignored potential semantic information behind the POIs. Researchers use this method to mine static functions from POIs [59] or measure the importance of different POI categories [41]. For deep learning in supervised learning, deep neural networks [60], deeper-feature convolutional neural networks [36], KDE [46], and hierarchical semantic cognition [26] have been used to identify urban functional zones. Their accuracy is a little bit higher than that of unsupervised learning, such as the clustering algorithm.

\subsection{Limitations and Future Work}

This study's results indicate that we can effectively identify urban functional zones, especially mixed functional zones, which is of great practical significance to the optimization and coordination of urban space. Nevertheless, this research has certain limitations. First, the deep learning method had little accuracy when identifying CNs. One reason is that there are few commercial lands to use as samples; the other is that it is difficult to separate commercial land from residential land using remote sensing. Because of the mixed functional zones, the UDL results were not accurate. There are multiple functional types in one zone, especially in economically developed urban central areas. The area ratio of different functional areas results in a lower accuracy of UDL when identical functional types are compared.

Second, this study used single datasets to identify urban functional zones, only from the functional perspective of land-use types, without integrating remote-sensing images and POI data; thus, the social and economic functions were ignored. In addition, although the division of units by road networks is feasible in many studies [21,61,62], there may be mixed functions in these units. As buildings are more detailed than road networks when dividing urban units, they have more potential for researching urban functions and 
structures $[14,38]$. In future research, we plan to integrate different datasets to exhaustively analyze the various functions of urban functional areas and explore urban functional structures. As a basic unit for identifying urban functions, we plan to use buildings, if possible, to determine functional areas more accurately.

\section{Conclusions}

As the basic unit of urban development and planning, urban functional zones can help urban planners develop better strategies, while also helping researchers to better understand the urban structure and environment. With the development of remote-sensing images and crowdsourced geographic information data, it has become easier to identify urban functional areas. We used Kuancheng District, Changchun, China, as the study area. We obtained 17,665 Gaode POIs, acquired on 30 September 2020, and used GF-2 images and OpenStreetMap road data for this study, which were acquired in September 2019 and 30 September 2020, respectively. Then, we used OSM road data for map segmentation and KDE, TF-IDF, and UDL methods to identify urban functional zones. These zones included residential zones (RN), commercial and commercial services facilities zones $(\mathrm{CN})$, public administration and public service zones (PN), industrial and mining storage zones (IN), and ecological zones (EN). Finally, we compared the results of the three methods with a field survey. The results suggested that deep learning had the lowest overall error $(43 \%)$ compared with KDE (83\%) and TF-IDF (71\%).

This study confirmed the feasibility of using remote-sensing images and POI data to detect urban functional zones. This approach can provide a perspective on urban transformation processes and prove useful for city management and planning. Further, we identified the current distribution of urban functional zones in the Kuancheng District. This can help city managers make adjustments, especially with regard to the Territorial Spatial Planning of Changchun (2020-2035). In general, using remote-sensing images with UDL methods to explore urban functional zones can provide new ideas for investigating urban functional areas and the urban spatial structure. Such work can support the intensive and economic use of urban land and achieve the sustainable development of cities. In future work, open social data will be combined with remote-sensing images to better identify urban functions, such as POI, mobile phone positioning, and social software check-in data.

Author Contributions: Conceptualization, D.W. and Y.Y.; methodology, Y.Y.; software, Y.Y. and Z.Y.; data curation, Y.Y. and S.Z.; writing — original draft preparation, Y.Y.; writing-review and editing, D.W. and Y.Y.; funding acquisition, D.W. and Y.Y. All authors have read and agreed to the published version of the manuscript.

Funding: This work was supported by the National Natural Science Foundation of China, grant number 42071255 .

Data Availability Statement: All data, models, and codes generated or used during the study appear in the submitted article.

Conflicts of Interest: The authors declare no conflict of interest.

\section{Appendix A}

The appendix is a table of types of original and aggregated POIs, which contains five labels at the first level, twenty-two labels at the second level, and the original labels at the third level. 
Table 1. Types of original and aggregated POIs.

\begin{tabular}{|c|c|c|}
\hline Aggregated Type & Big Category* & Mid Category * \\
\hline Residential & Residential Area & Residential Area \\
\hline & Accommodation Service & Hotel, Hostel, Accommodation Service Related \\
\hline & Auto Dealers & $\begin{array}{l}\text { Audi Franchised Sales, BMW Franchised Sales, Porsche Franchised Sales, Beiben Trucks } \\
\text { Sales, BAIC MOTOR Sales, Honda Franchised Sales, Peugeot Citroen Franchised Sales, } \\
\text { Peugeot Citroen, Chengdu Dayun Automotive Sales, Volkswagen Franchised Sales, } \\
\text { MAN Sales, Dongfeng Truck Sales, DFM Franchised Sales, Ferrari Franchised Sales, Fiat } \\
\text { Franchised Sales, Toyota Franchised Sales, Ford Franchised Sales, Foton Truck Sales, } \\
\text { Qoros Sales, GAC Trumpchi Sales, Haima Sales, Hongqi Sales, CAMC Sales, Truck Sales, } \\
\text { Geely Franchised Sales, JAC Truck Sales, JAC Sales, JAGUAR Franchised Sales, Chrysler } \\
\text { Franchised Sales, Renault Franchised Sales, Land Rover Franchised Sales, } \\
\text { Mercedes-Benz Truck Sales, Mercedes-Benz Franchised Sales, MG Sales, Luxgen Sales, } \\
\text { Chery Franchised Sales, KIA Franchised Sales, Automobile Sales, Nissan Franchised } \\
\text { Sales, ROEWE Sales, Mitsubishi Franchised Sales, Shaanxi Heavy-duty Truck Sales, } \\
\text { Subaru Franchised Sales, SCANIA Sales, General Motors Franchised Sales, Volvo Truck } \\
\text { Sales, Hyundai Franchised Sales, FAW Jiefang Sales, Chang'an Sales, Great Wall Sales, } \\
\text { SINOTRUK Sales }\end{array}$ \\
\hline $\begin{array}{c}\text { Commercial And } \\
\text { Commercial Services } \\
\text { Facilities }\end{array}$ & Auto Repair & $\begin{array}{l}\text { Audi Franchised Repair, BMW Franchised Repair, Porsche Franchised Repair, Beiben } \\
\text { Trucks Repair, BAIC MOTOR Repair, Honda Franchised Repair, Peugeot Citroen } \\
\text { Franchised Repair, Peugeot Citroen, Chengdu Dayun Automotive Repair, Volkswagen } \\
\text { Franchised Repair, MAN Repair, Dongfeng Truck Repair, DFM Franchised Repair, } \\
\text { Ferrari Franchised Repair, Fiat Franchised Repair, Toyota Franchised Repair, Ford } \\
\text { Franchised Repair, Foton Truck Repair, Qoros Repair, GAC Trumpchi Repair, Haima } \\
\text { Repair, Hongqi Repair, CAMC Repair, Truck Repair, Geely Franchised Repair, JAC Truck } \\
\text { Repair, JAC Repair, JAGUAR Franchised Repair, Chrysler Franchised Repair, Renault } \\
\text { Franchised Repair, Land Rover Franchised Repair, Mercedes-Benz Truck Repair, } \\
\text { Mercedes-Benz Franchised Repair, MG Repair, Luxgen Repair, Chery Franchised Repair, } \\
\text { KIA Franchised Repair, Automobile Repair, Automobile Comprehensive Repair, Nissan } \\
\text { Franchised Repair, ROEWE Repair, Mitsubishi Franchised Repair, Shaanxi Heavy-duty } \\
\text { Truck Repair, Subaru Franchised Repair, SCANIA Repair, General Motors Franchised } \\
\text { Repair, Volvo Truck Repair, Hyundai Franchised Repair, FAW Jiefang Repair, Chang'an } \\
\text { Repair, Great Wall Repair, SINOTRUK Repair }\end{array}$ \\
\hline
\end{tabular}

Auto Service

Charging Station, Used Automobile Dealer, Filling Station, Filling Station, Other Energy

Station, Automobile Service Related, Automobile Rescue, Automobile Club, Automobile Parts Sales, Automobile Maintenance/Decoration, Automobile Rental, Car Wash

\begin{tabular}{cc}
\hline Commercial House & Industrial Park, Building, Commercial House Related \\
\hline Daily Life Service & $\begin{array}{c}\text { Move Service, Lottery Store, Electric Supply Service Office, Telecom Office, Travel } \\
\text { Agency, Beauty and Hairdressing Store, Job Center, Funeral Facilities, Photo Finishing, } \\
\text { Daily Life Service Place, Professional Service Firm, Ticket Office, Repair Store, Logistics } \\
\text { Service, Laundry, Bath \& Massage Center, Information Centre, Baby Service Place, Post } \\
\text { Office, Agency, Water Supply Service Office }\end{array}$ \\
\hline $\begin{array}{c}\text { Finance \& Insurance } \\
\text { Service }\end{array}$ & $\begin{array}{c}\text { Insurance Company, Finance Company, Finance \& Insurance Service Institution, Bank, } \\
\text { Bank Related, Securities Company, ATM }\end{array}$ \\
\hline Food \& Beverages & $\begin{array}{c}\text { Food \& Beverages Related, Tea House, Bakery, Coffee House, Fast Food Restaurant, } \\
\text { Icecream Shop, Dessert House, Foreign Food Restaurant, Leisure Food Restaurant, } \\
\text { Chinese Food Restaurant }\end{array}$ \\
\hline Motorcycle Service & $\begin{array}{c}\text { Motorcycle Service Related, Motorcycle Repair, Motorcycle Sales } \\
\text { Shopping }\end{array}$ \\
\hline $\begin{array}{c}\text { Convenience Store, Supermarket, Clothing Store, Personal Care Items Shop, Shopping } \\
\text { Related Places, Plants \& Pet Market, Home Electronics Hypermarket, Home Building } \\
\text { Materials Market, Shopping Plaza, Commercial Street, Special Trade House, Sports Store, } \\
\text { Stationary Store, Franchise Store, Comprehensive Market }\end{array}$ \\
\hline
\end{tabular}


Table 1. Cont

\begin{tabular}{|c|c|c|}
\hline Aggregated Type & Big Category * & Mid Category * \\
\hline \multirow{6}{*}{$\begin{array}{l}\text { Public Government And } \\
\text { Public Service }\end{array}$} & Culture \& Education & School \\
\hline & $\begin{array}{l}\text { Governmental } \\
\text { Organization \& Social } \\
\text { Group }\end{array}$ & $\begin{array}{c}\text { Industrial and Commercial Taxation Institution, Public Security Organization, Traffic } \\
\text { Vehicle Management, Democratic Party, Social Group, Foreign Organization, } \\
\text { Governmental Organization, Governmental \& Social Groups Related }\end{array}$ \\
\hline & Medical Service & $\begin{array}{l}\text { Veterinary Hospital, Emergency Center, Disease Prevention Institution, Medical and } \\
\text { Health Care Service Place, Pharmacy, Clinic, Special Hospital, Hospital }\end{array}$ \\
\hline & Public Facility & Newsstand, Public Toilet, Public Facility, Public Phone, Emergency Shelter \\
\hline & $\begin{array}{l}\text { Science, Culture \& } \\
\text { Education Service }\end{array}$ & $\begin{array}{c}\text { Museum, Media Organization, Archives Hall, Convention \& Exhibition Center, Driving } \\
\text { School, Science \& Technology Museum, Science \& Education Cultural Place, Research } \\
\text { Institution, Art Gallery, Training Institution, Planetarium, Library, Cultural Palace, Arts } \\
\text { Organization, School, Exhibition Hall }\end{array}$ \\
\hline & Sports \& Recreation & $\begin{array}{c}\text { Holiday \& Nursing Resort, Golf Related, Sports \& Recreation Places, Recreation Place, } \\
\text { Theatre \& Cinema, Recreation Center, Sports Stadium }\end{array}$ \\
\hline $\begin{array}{l}\text { Industrial And Mining } \\
\text { Storage }\end{array}$ & Enterprises & $\begin{array}{c}\text { Factory, Company, Enterprises, Farming, Forestry, Animal Husbandry and Fishery Base, } \\
\text { Famous Enterprise }\end{array}$ \\
\hline Ecological & Tourist Attraction & Scenery Spot, Tourist Attraction Related, Park \& Square, Park \& Plaza \\
\hline \multirow{3}{*}{ Transportation } & Pass Facilities & Gate of Buildings, Gate of Street House, Pass Facilities, Virtual Gate \\
\hline & Road Furniture & Road Furniture, Service Area, Traffic Light, Warning Sign, Signpost, Toll Gate \\
\hline & Transportation Service & $\begin{array}{c}\text { Commuter Bus Station, Taxi, Subway Station, Port \& Marina, Bus Station, Border } \\
\text { Crossing, Railway Station, Airport Related, Transportation Service Related, Ferry Station, } \\
\text { Light Rail Station, Ropeway Station, Parking Lot, Coach Station }\end{array}$ \\
\hline
\end{tabular}

Note: Big category * and mid category* are original types of points of interest downloaded from https://lbs.amap.com/api/webservice/ download (accessed on 30 September 2020).

\section{References}

1. Seto, K.C.; Reenberg, A.; Boone, C.G.; Fragkias, M.; Haase, D.; Langanke, T.; Marcotullio, P.; Munroe, D.K.; Olah, B.; Simon, D. Urban land teleconnections and sustainability. Proc. Natl. Acad. Sci. USA 2012, 109, 7687-7692. [CrossRef] [PubMed]

2. Ma, Y.; Liu, S.; Xue, G.; Gong, D. Soft Sensor with Deep Learning for Functional Region Detection in Urban Environments. Sensors 2020, 20, 3348. [CrossRef]

3. Obaco, M.; Royuela, V.; Xavier, V. Identifying functional urban areas in ecuador using a varying travel time approach. Geogr. Anal. 2020, 52, 107-124. [CrossRef]

4. Ma, S.; Long, Y. Functional urban area delineations of cities on the Chinese mainland using massive Didi ride-hailing records. Cities 2020, 97, 102532. [CrossRef]

5. Niu, H.; Silva, E.A. Delineating urban functional use from points of interest data with neural network embedding: A case study in Greater London. Comput. Environ. Urban Syst. 2021, 88, 101651. [CrossRef]

6. Huang, X.; Yang, J.; Li, J.; Wen, D. Urban functional zone mapping by integrating high spatial resolution nighttime light and daytime multi-view imagery. ISPRS J. Photogramm. Remote Sens. 2021, 175, 403-415. [CrossRef]

7. Wang, F.; Dong, W.; Zhao, Z.; Wang, H.; Li, W.; Chen, G.; Wang, F.; Zhao, Y.; Huang, J.; Zhou, T. Heavy metal pollution in urban river sediment of different urban functional areas and its influence on microbial community structure. Sci. Total Environ. 2021, 778, 146383. [CrossRef] [PubMed]

8. Song, J.; Tong, X.; Wang, L.; Zhao, C.; Prishchepov, A.V. Monitoring finer-scale population density in urban functional zones: A remote sensing data fusion approach. Landsc. Urban. Plan. 2019, 190, 103580. [CrossRef]

9. Ke, X.; Men, H.; Zhou, T.; Li, Z.; Zhu, F. Variance of the impact of urban green space on the urban heat island effect among different urban functional zones: A case study in Wuhan. Urban. For. Urban. Green. 2021, 62, 127159. [CrossRef]

10. Song, J.; Zhao, C.; Lin, T.; Li, X.; Prishchepov, A.V. Spatio-temporal patterns of traffic-related air pollutant emissions in different urban functional zones estimated by real-time video and deep learning technique. J. Clean. Prod. 2019, 238, 238. [CrossRef]

11. Zhang, T.; Sun, L.; Yao, L.; Rong, J. Impact analysis of land use on traffic congestion using real-time traffic and POI. J. Adv. Transp. 2017, 2017, 7164790. [CrossRef]

12. Heiden, U.; Heldens, W.; Roessner, S.; Segl, K.; Esch, T.; Mueller, A. Urban structure type characterization using hyperspectral remote sensing and height information. Landsc. Urban. Plan. 2012, 105, 361-375. [CrossRef]

13. Myint, S.W.; Gober, P.; Brazel, A.; Grossman-Clarke, S.; Weng, Q. Per-pixel vs. object-based classification of urban land cover extraction using high spatial resolution imagery. Remote Sens. Environ. 2011, 115, 1145-1161. [CrossRef]

14. Chen, Y.; Liu, X.; Li, X.; Liu, X.; Yao, Y.; Hu, G.; Xu, X.; Pei, F. Delineating urban functional areas with building-level social media data: A dynamic time warping (DTW) distance based k-medoids method. Landsc. Urban Plan. 2017, 160, 48-60. [CrossRef]

15. Tu, W.; Cao, J.; Yue, Y.; Shaw, S.-L.; Zhou, M.; Wang, Z.; Chang, X.; Xu, Y.; Li, Q. Coupling mobile phone and social media data: A new approach to understanding urban functions and diurnal patterns. Int. J. Geogr. Inf. Sci. 2017, 31, 2331-2358. [CrossRef] 
16. Liu, X.; Jiao, P.; Yuan, N.; Wang, W. Identification of multi-attribute functional urban areas under a perspective of community detection: A case study. Phys. A Stat. Mech. Its Appl. 2016, 462, 827-836. [CrossRef]

17. Klapka, P.; Halás, M.; Erlebach, M.; Tonev, P.; Bednář, M. A Multistage agglomerative approach for defining functional regions of the czech republic: The use of 2001 commuting data/Vícestupňový aglomerační přístup k vymezení funkčních regionů České republiky: Využití údajů o dojížd'ce z roku 2001. Morav. Geogr. Rep. 2014, 22, 2-13. [CrossRef]

18. Gao, S.; Janowicz, K.; Couclelis, H. Extracting urban functional regions from points of interest and human activities on locationbased social networks. Trans. GIS 2017, 21, 446-467. [CrossRef]

19. Miao, R.; Wang, Y.; Li, S. Analyzing urban spatial patterns and functional zones using sina weibo POI data: A case study of Beijing. Sustainability 2021, 13, 647. [CrossRef]

20. Hu, S.; He, Z.; Wu, L.; Yin, L.; Xu, Y.; Cui, H. A framework for extracting urban functional regions based on multiprototype word embeddings using points-of-interest data. Comput. Environ. Urban Syst. 2019, 80, 101442. [CrossRef]

21. Hong, Y.; Yao, Y. Hierarchical community detection and functional area identification with OSM roads and complex graph theory. Int. J. Geogr. Inf. Sci. 2019, 33, 1569-1587. [CrossRef]

22. Du, S.; Du, S.; Liu, B.; Zhang, X.; Zheng, Z. Large-scale urban functional zone mapping by integrating remote sensing images and open social data. GISci. Remote Sens. 2020, 57, 411-430. [CrossRef]

23. Cao, R.; Tu, W.; Yang, C.; Li, Q.; Liu, J.; Zhu, J.; Zhang, Q.; Li, Q.; Qiu, G. Deep learning-based remote and social sensing data fusion for urban region function recognition. ISPRS J. Photogramm. Remote Sens. 2020, 163, 82-97. [CrossRef]

24. Ma, T.; Zhou, C.; Pei, T.; Haynie, S.; Fan, J. Quantitative estimation of urbanization dynamics using time series of DMSP/OLS nighttime light data: A comparative case study from China's cities. Remote Sens. Environ. 2012, 124, 99-107. [CrossRef]

25. Tu, W.; Hu, Z.; Li, L.; Cao, J.; Jiang, J.; Li, Q.; Li, Q. Portraying urban functional zones by coupling remote sensing imagery and human sensing data. Remote Sens. 2018, 10, 141. [CrossRef]

26. Zhang, X.; Du, S.; Wang, Q. Hierarchical semantic cognition for urban functional zones with VHR satellite images and POI data. ISPRS J. Photogramm. Remote Sens. 2017, 132, 170-184. [CrossRef]

27. Wang, Y.; Wang, T.; Tsou, M.-H.; Li, H.; Jiang, W.; Guo, F. Mapping dynamic urban land use patterns with crowdsourced geo-tagged social media (Sina-Weibo) and commercial points of interest collections in Beijing, China. Sustainability 2016, 8, 1202. [CrossRef]

28. Cao, X.; Zhou, F.; Xu, L.; Meng, D.; Xu, Z.; Paisley, J. Hyperspectral image classification with markov random fields and a convolutional neural network. IEEE Trans. Image Process. 2018, 27, 2354-2367. [CrossRef]

29. Tian, X.; Wang, L.; Meng, X. Image Semantic Segmentation Based on Deep Learning; Maritime Press: Beijing, China, 2019 ; pp. 1-20.

30. Zhuang, J.; Zhang, J.; Xu, Y. Deep Learning Image Recognition Technology; China Machine Press: Beijing, China, $2020 ;$ pp. 1-17.

31. Tong, X.-Y.; Xia, G.-S.; Lu, Q.; Shen, H.; Li, S.; You, S.; Zhang, L. Land-cover classification with high-resolution remote sensing images using transferable deep models. Remote Sens. Environ. 2020, 237, 111322. [CrossRef]

32. Li, K.; Wan, G.; Cheng, G.; Meng, L.; Han, J. Object detection in optical remote sensing images: A survey and a new benchmark. ISPRS J. Photogramm. Remote Sens. 2020, 159, 296-307. [CrossRef]

33. Wu, X.; Sahoo, D.; Hoi, S.C.H. Recent advances in deep learning for object detection. Neurocomputing 2020, 396, 39-64. [CrossRef]

34. Ma, L.; Liu, Y.; Zhang, X.; Ye, Y.; Yin, G.; Johnson, B.A. Deep learning in remote sensing applications: A meta-analysis and review. ISPRS J. Photogramm. Remote Sens. 2019, 152, 166-177. [CrossRef]

35. Diakogiannis, F.I.; Waldner, F.; Caccetta, P.; Wu, C. ResUNet-a: A deep learning framework for semantic segmentation of remotely sensed data. ISPRS J. Photogramm. Remote Sens. 2020, 162, 94-114. [CrossRef]

36. Bao, H.; Ming, D.; Guo, Y.; Zhang, K.; Zhou, K.; Du, S. DFCNN-based semantic recognition of urban functional zones by integrating remote sensing data and POI data. Remote Sens. 2020, 12, 1088. [CrossRef]

37. Hu, L.; Sun, T.; Wang, L. Evolving urban spatial structure and commuting patterns: A case study of Beijing, China. Transp. Res. Part. D Transport. Environ. 2018, 59, 11-22. [CrossRef]

38. Xing, H.; Meng, Y. Integrating landscape metrics and socioeconomic features for urban functional region classification. Comput. Environ. Urban Syst. 2018, 72, 134-145. [CrossRef]

39. Hu, Y.; Han, Y. Identification of urban functional areas based on POI data: A case study of the Guangzhou economic and technological development zone. Sustainability 2019, 11, 1385. [CrossRef]

40. Zhai, W.; Bai, X.; Shi, Y.; Han, Y.; Peng, Z.-R.; Gu, C. Beyond Word2vec: An approach for urban functional region extraction and identification by combining Place2vec and POIs. Comput. Environ. Urban Syst. 2019, 74, 1-12. [CrossRef]

41. Yao, Z.; Fu, Y.; Liu, B.; Hu, W.; Xiong, H. Representing urban functions through zone embedding with human mobility patterns. In Proceedings of the Twenty-Seventh International Joint Conference on Artificial Intelligence (IJCAI-18), Stockholm, Sweden, 13-19 July 2018.

42. Halás, M.; Klapka, P.; Tonev, P. The use of migration data to define functional regions: The case of the Czech Republic. Appl. Geogr. 2016, 76, 98-105. [CrossRef]

43. Lou, X.; Xie, J.; Wang, S. The study of Changchun city function subarea and the adjustive problems of the industry space structure. J. Northeast. Norm. Univ. (Nat. Sci. Ed.) 2004, 3, 101-107.

44. Liu, X.; Long, Y. Automated identification and characterization of parcels with OpenStreetMap and points of interest. Environ. Plan. B Plan. Des. 2015, 43, 341-360. [CrossRef] 
45. Fan, J. Spatial organization pathway for territorial function-structure: Discussion on implementation of major function zoning strategy in territorial spatial planning. Geogr. Res. 2019, 38, 2373-2387.

46. Luo, S.; Liu, Y.; Du, M.; Gao, S.; Wang, P.; Liu, X. The influence of spatial grid division on the layout analysis of urban functional areas. ISPRS Int. J. Geo-Inf. 2021, 10, 189. [CrossRef]

47. Malik, I.; Dewancker, B. Identification of population growth and distribution, based on urban zone functions. Sustainability 2018, 10, 930. [CrossRef]

48. Ronneberger, O.; Fischer, P.; Brox, T. U-Net: Convolutional networks for biomedical image segmentation. In Proceedings of the International Conference on Medical Image Computing and Computer-Assisted Intervention, Berlin, Germany, 5-9 October 2015; Volume 9351, pp. 234-241.

49. Peng, D.; Zhang, Y.; Guan, H. End-to-end change detection for high resolution satellite images using improved UNet++. Remote Sens. 2019, 11, 1382. [CrossRef]

50. He, N.; Fang, L.; Plaza, A. Hybrid first and second order attention Unet for building segmentation in remote sensing images. Sci. China Inf. Sci. 2020, 63, 69-80. [CrossRef]

51. Pontius, R.G. Component intensities to relate difference by category with difference overall. Int. J. Appl. Earth Obs. Geoinf. 2019, 77, 94-99. [CrossRef]

52. Whiteside, T.G.; Bartolo, R.E. Use of WorldView-2 time series to establish a wetland monitoring program for potential offsite impacts of mine site rehabilitation. Int. J. Appl. Earth Obs. Geoinf. 2015, 42, 24-37. [CrossRef]

53. Wu, C.; Ye, X.; Ren, F.; Du, Q. Check-in behaviour and spatio-temporal vibrancy: An exploratory analysis in Shenzhen, China. Cities 2018, 77, 104-116. [CrossRef]

54. Mc Cutchan, M.; Comber, A.J.; Giannopoulos, I.; Canestrini, M. Semantic boosting: Enhancing deep learning based LULC classification. Remote Sens. 2021, 13, 3197. [CrossRef]

55. Du, S.; Du, S.; Liu, B.; Zhang, X. Mapping large-scale and fine-grained urban functional zones from VHR images using a multi-scale semantic segmentation network and object based approach. Remote Sens. Environ. 2021, 261, 112480. [CrossRef]

56. Xu, G.; Zhou, Z.; Jiao, L.; Zhao, R. Compact urban form and expansion pattern slow down the decline in urban densities: A global perspective. Land Use Policy 2020, 94, 104563. [CrossRef]

57. Li, H.; Zhou, Y.; Li, X.; Meng, L.; Wang, X.; Wu, S.; Sodoudi, S. A new method to quantify surface urban heat island intensity. Sci. Total Environ. 2018, 624, 262-272. [CrossRef] [PubMed]

58. Thakali, L.; Kwon, T.J.; Fu, L. Identification of crash hotspots using kernel density estimation and kriging methods: A comparison. J. Mod. Transp. 2015, 23, 93-106. [CrossRef]

59. Kong, X.; Li, M.; Li, J.; Tian, K.; Hu, X.; Xia, F. CoPFun: An urban co-occurrence pattern mining scheme based on regional function discovery. World Wide Web 2018, 22, 1029-1054. [CrossRef]

60. Ye, C.; Zhang, F.; Mu, L.; Gao, Y.; Liu, Y. Urban function recognition by integrating social media and street-level imagery. Environ. Plan. B Urban. Anal. City Sci. 2020, 48, 1430-1444. [CrossRef]

61. Hu, T.; Yang, J.; Li, X.; Gong, P. Mapping urban land use by using landsat images and open social data. Remote Sens. $2016,8,151$. [CrossRef]

62. Lan, T.; Shao, G.; Xu, Z.; Tang, L.; Sun, L. Measuring urban compactness based on functional characterization and human activity intensity by integrating multiple geospatial data sources. Ecol. Indic. 2021, 121, 107177. [CrossRef] 